\section{Associação entre fatores contextuais e auto-avaliação de saúde: uma revisão sistemática de estudos multinível}

\author{
Association between contextual factors and \\ self-rated health: a systematic review \\ of multilevel studies
}

\author{
1 Instituto de Comunicação \\ e Informação Científica \\ e Tecnológica em Saúde, \\ Fundação Oswaldo Cruz, \\ Rio de Janeiro, Brasil. \\ 2 Escola Nacional de Saúde \\ Pública Sergio Arouca, \\ Fundação Oswaldo Cruz, \\ Rio de Janeiro, Brasil. \\ ${ }^{3}$ Instituto de Medicina \\ Social, Universidade do \\ Estado do Rio de Janeiro, \\ Rio de Janeiro, Brasil. \\ Correspondência \\ S. M. Santos \\ Departamento de \\ Informações em Saúde, \\ Instituto de Comunicação \\ e Informações Científica \\ e Tecnológica em Saúde, \\ Fundação Oswaldo Cruz. \\ Av. Brasil 4365, \\ Rio de Janeiro, RJ \\ 21045-900, Brasil. \\ smsantos@fiocruz.br
}

\begin{abstract}
The influence of residential characteristics on self-rated health has received little research attention, especially in Brazil. This study summarizes the available evidence on the association between contextual factors and self-rated health, using a systematic review of articles published from January 1995 to August 2005. We searched for the terms neighbourhood or neighborhood, ecological, contextual, environment, and community, combined with self-rated health, selfreported health, and multilevel or hierarchical in digital bases. Most of the 18 reviewed studies analyzed socioeconomic indicators, while some investigated psychosocial variables and a few included physical environmental indicators. Spatial units of reference varied from census tracts to States. Differences among scales of contextual analysis and several indicators, with different categories, were identified. The associations corroborate the hypothesis that neighborhood context influences self-rated health, beyond the effect of individual factors. Physical and psychosocial neighborhood characteristics are important contextual factors in the determination of self-rated health. Worse socioeconomic neighborhood conditions have a negative effect on health, thereby increasing the odds of worse self-rated health.
\end{abstract}

Health Status; Socioeconomic Factors; Review Literature
Simone M. Santos 1

Dóra Chor 2

Guilherme Loureiro Werneck 3

Evandro Silva Freire Coutinho 2

\section{Introdução}

A influência de características individuais e contextuais do local de moradia (vizinhança) na auto-avaliação de saúde ainda é um tema pouco estudado, especialmente no Brasil.

A auto-avaliação de saúde é um indicador cada vez mais utilizado em pesquisas epidemiológicas. Diversas investigações apontam que a percepção da saúde prediz, consistentemente, a mortalidade e o declínio funcional em idosos 1 . De fato, a auto-avaliação de saúde tem se revelado melhor preditor de mortalidade do que diversas medidas objetivas do estado de saúde 1 , refletindo a percepção integrada do indivíduo que inclui as dimensões biológica, psicológica e social da saúde 2 .

Um grande conjunto de características individuais que influenciam desfechos de saúde já foi bem estabelecido. Fatores sócio-econômicos como educação, renda, desemprego, hábitos de vida são determinantes conhecidos da saúde individual ${ }^{3}$ e, em particular, da auto-avaliação da saúde 4,5,6. Dentre os determinantes da auto-avaliação de saúde, destaca-se a posição sócio-econômica individual, essa associação tem sido amplamente demonstrada em diversos estudos 7,8,9,10

Na última década, muitas áreas de investigação em ciências sociais e epidemiologia têm buscado refinar a pesquisa sobre as relações entre indivíduos e o contexto em que vivem. Há muitas 
evidências de que a saúde individual varia entre diferentes contextos, áreas e países. Alguns autores questionam se essas variações são determinadas por fenômenos que atuam em níveis ecológicos (características contextuais comuns a um conjunto de pessoas, que condicionam sua localização) ou apenas por efeitos composicionais (características relacionadas ao sexo, idade e posição social dos indivíduos que compõem o conjunto de pessoas estudado) 11.

Os estudos dos efeitos de características das coletividades ou grupos nos desfechos do nível individual foram denominados de análise contextual ou análise multinível. Dessa forma podem ser investigadas, tanto variações entre indivíduos, quanto entre grupos e a contribuição de cada um desses níveis no desfecho de interesse. No Brasil, há poucos estudos sobre o tema 4,5 , e nenhum estudo multinível.

\section{Características do contexto potencialmente} importantes para a auto-avaliação de saúde

Os efeitos contextuais de vizinhança na saúde individual têm sido empiricamente demonstrados levando-se em conta uma série de fatores individuais como idade, raça/etnia, renda, educação, classe social, ou condição de saúde. Diversas características de vizinhança têm sido investigadas, podendo ser agrupadas nas dimensões sócioeconômica, física e psicossocial do ambiente.

Estudos recentes mostram que indicadores sócio-econômicos da vizinhança estão associados com a auto-avaliação de saúde ${ }^{12}$, com hábitos de vida 13 e influenciam nos maus-tratos infantis 14. Vários mecanismos explicativos têm sido propostos. Conforme Macintyre et al. 15, as influências do ambiente físico e social podem ser classificadas por meio de cinco dimensões da vizinhança capazes de promover ou prejudicar a saúde: condições físicas do ambiente compartilhado por todos os residentes de uma localidade (por exemplo, qualidade do ar); disponibilidade de ambientes saudáveis de moradia, trabalho e em áreas de lazer (por exemplo, residências com boa estrutura, áreas seguras de lazer para crianças e adultos); serviços públicos ou privados que dêem suporte às atividades diárias (por exemplo, educação, transporte, limpeza urbana); recursos sócio-culturais da localidade (por exemplo, história política, grau de integração da comunidade); e a reputação de uma área (por exemplo, como a área é percebida pelos seus residentes e pelos administradores públicos). Conforme salientam Lynch \& Kaplan 16, posição sócio-econômica expressa estruturas particulares da sociedade, sendo um poderoso modo pelo qual as exposições causam danos à saúde e, também, um indicador da possibilidade de possuir recursos particulares para a promoção da saúde.

Na Suécia, Malmtröm et al. 17 relataram associação entre características individuais (nível educacional, obesidade, fumo e atividade física), assim como contextuais (índice de carência e de privação) e auto-avaliação de saúde. Subramanian \& Kawachi 18 demonstraram que a desigualdade de renda dos estados americanos exerce um efeito global importante na auto-avaliação de saúde individual, especialmente na população negra, mesmo quando efeitos dos fatores individuais são controlados.

Características físicas do ambiente como aparência, poluição atmosférica e sonora, e a infra-estrutura de serviços (por exemplo, serviços de saúde, mercados) podem facilitar ou dificultar o acesso a serviços e a atividades relacionadas à saúde. Sinais de desordem física refletem a deterioração do espaço urbano (por exemplo, pichações em imóveis, carros abandonados, e lixo acumulado nas ruas) e estão associadas a piores condições de saúde 19,20. Boa iluminação, calçadas limpas e amplas, serviço de transporte público facilitam o deslocamento de pessoas portadoras de necessidades especiais, aumentando sua atividade física e sua saúde 21 .

As características psicossociais compreendem os diversos processos sociais que atuam na organização social das vizinhanças. O acúmulo do que vem sendo denominado "capital social", por exemplo, está relacionado aos recursos disponíveis nas estruturas sociais. Esses recursos podem ser utilizados pelos indivíduos para desencadear ações coletivas, sendo o capital social um subproduto das relações sociais e da participação civil em organizações informais e formais. Os recursos disponíveis podem ser materiais, mas também, e particularmente, não-materiais como confiança, normas de reciprocidade, assistência mútua, e mobilização comunitária 7. Dentro de uma abordagem geográfica, o capital social se concretiza na relação singular dos grupos sociais com seu território e a presença de equipamentos e recursos na vizinhança.

Confiança, normas de reciprocidade e participação em organizações voluntárias têm sido relacionadas a desfechos de saúde em regiões, assim como em pequenas áreas e vizinhanças 22,23,24. Kawachi et al. 22, por exemplo, relatam que o baixo nível de capital social aumentou a chance de auto-avaliação de saúde ruim em moradores dos diferentes estados americanos, para além dos fatores individuais (baixa renda, baixo nível de escolaridade, fumo). Sampson et al. 25 redefiniram o capital social utilizando o conceito de eficácia coletiva e, em Chicago, encontraram que a eficácia coletiva explica porção sig- 
nificante da variação dos hábitos de delinqüência na vizinhança. A eficácia coletiva também está associada à auto-avaliação de saúde 12 .

\section{Definição e mensuração de vizinhança}

Abordagens utilizando a vizinhança (neighborhood, em inglês) como unidade de análise apresentaram crescimento expressivo na última década, especialmente influenciadas pelos estudos norte-americanos. Em contrapartida, essa abordagem ainda é pouco utilizada na pesquisa em saúde pública brasileira. Chaskin 26, por intermédio de uma revisão de literatura, apresenta diversos conceitos e implicações importantes sobre as abordagens de vizinhança. O autor destaca que vizinhança é uma construção espacial que denota uma unidade geográfica cujos residentes dividem proximidade e as circunstâncias que advém dela. A vizinhança é uma subunidade de uma área maior e é usualmente, mas não exclusivamente, residencial. Uma definição clássica é dada por Keller (1968, apud Chaskin 26, p. 522) "áreas distintas nas quais grandes unidades espaciais podem ser subdivididas (...) A distinção dessas áreas baseia-se em (...) limites geográficos, ou características étnicas ou culturais dos seus habitantes, ou sensação compartilhada de pertencimento pela qual as pessoas se sentem psicologicamente unidas, ou pelo uso concentrado de serviços para compras, lazer, e aprendizado". No contexto urbano, a vizinhança seria de fato, freqüentemente, considerada como a unidade primordial de solidariedade, real ou potencial, e de coesão social 26 .

Vizinhança concebida como unidade espacial, do ponto de vista econômico, político, e como sistema social, implica a existência de limites e de associações que a definem e a diferenciam do seu entorno. Ainda que os indivíduos possam não perceber suas amizades e redes de suporte em termos do espaço da vizinhança, conjuntos de redes interpessoais podem ser identificados nos limites de unidades como a vizinhança.

Na medida em que cresce a evidência de que os problemas de saúde estão fortemente associados às características sociais das comunidades $22,27,28$, e não somente às características dos indivíduos, estudos empregando recortes de vizinhança vêm sendo cada vez mais utilizados na Saúde Pública. Este recorte, que facilita a mensuração de processos sociais envolvidos nas disparidades de saúde nas cidades modernas, combinado com os sistemas de informação geográfica (SIG), permite aprofundar o entendimento das dinâmicas espaciais, pois apresentam maior flexibilidade para reunir informações de diversas escalas espaciais 29 .
Os desenhos de estudo que incluem múltiplos níveis hierárquicos são os mais indicados para avaliar a importância de características do contexto e dos fatores individuais na saúde, permitindo a mensuração mais refinada da contribuição de cada um dos níveis. Além disso, são necessários porque a violação do pressuposto de independência nos modelos não hierárquicos pode levar à estimação incorreta do erro-padrão dos parâmetros e, possivelmente, a inferências incorretas a respeito dos efeitos das características de vizinhança.

Para se traçar um panorama crítico sobre a influência dos fatores contextuais de vizinhança na auto-avaliação de saúde, realizou-se revisão sistemática da bibliografia publicada sobre esse tema, buscando evidenciar as principais características metodológicas desses estudos. Especificamente, este estudo objetivou identificar quais características de contexto de moradia (vizinhança) vêm sendo estudadas; quais unidades espaciais foram analisadas para a seleção das características de contexto e da vizinhança; e quais resultados foram encontrados para a associação entre características da vizinhança e autoavaliação de saúde. Espera-se que a partir dessa revisão, seja possível realizar uma síntese sobre a participação dos diversos fatores contextuais na determinação da auto-avaliação de saúde, sugerir mecanismos envolvidos nestes processos $\mathrm{e}$ apontar indicadores contextuais que devam ser considerados para o estudo da auto-avaliação de saúde no Brasil.

\section{Metodologia}

Realizou-se a busca de referências bibliográficas nas bases SciSearch, ISI Web of Science, PubMed (MEDLINE), SciELO, LILACS, em setembro de 2005, utilizando-se cada um dos termos neighborhood (ou neighbourhood), ecological, contextual, environment, community, em combinação com self-rated health ou self-reported health, e também com multilevel ou hierarchical.

Foram incluídos estudos originais publicados entre janeiro de 1995 e agosto de 2005, de todos os tipos de delineamento, que utilizaram análise multinível e com resumos disponíveis em língua inglesa, portuguesa, espanhola ou francesa.

Em relação ao desfecho, foram selecionados estudos em que a auto-avaliação de saúde de populações adultas e seus subgrupos foi medida pela pergunta "De um modo geral, em comparação a pessoas da sua idade, como você considera o seu próprio estado de saúde?", ou similar (independentemente do fraseamento) com opções de resposta do tipo Likert. Nesta abordagem, as 
respostas são geralmente apresentadas por meio de cinco opções: muito boa; boa; regular; ruim; muito ruim; existindo, porém, algumas variações agregadas para quatro ou três opções. Foram excluídos estudos cujo desfecho era "bem-estar" ou medidas de prevalência de eventos adversos à saúde, e também estudos cujo desfecho era autoavaliação de saúde bucal ou mental.

Quanto à exposição, foram incluídos os estudos em que a característica contextual foi derivada de informações primárias e/ou de bancos de dados secundários, desde que relativa a recortes territoriais e suas agregações (por exemplo, vizinhanças, municípios etc.).

Após a leitura completa de cada um dos artigos, os dados pertinentes foram extraídos para um formulário que foi desenvolvido especificamente para este estudo. A apresentação dos resultados foi sistematizada com o uso de tabelas.

Para facilitar a comparação entre estudos similares, os artigos selecionados foram agrupados por escala geográfica de abrangência (base da população alvo) dos processos que relacionavam contexto e auto-avaliação de saúde (cidades, estados e regiões, países representados por grandes áreas e países representados por pequenas áreas). Destaca-se que a escala geográfica de abrangência é a área onde vive o conjunto da população alvo do estudo, enquanto as unidades espaciais de análise são as subunidades que compõem esta área. Portanto, as características de contexto referem-se às unidades espaciais de análise que representam a escala geográfica do universo do estudo (por exemplo, a escala geográfica de abrangência de um estudo pode ser um país, e as unidades espaciais de análise podem ser compostas por setores censitários, vizinhanças, distritos ou estados que o compõem).

Os indicadores de contexto utilizados nos artigos revisados foram agrupados em três dimensões: características sócio-econômicas, características físicas, e características psicossociais do ambiente. No caso de alguns indicadores compostos por mais de uma dessas dimensões, a classificação correspondeu à dimensão predominante dos seus componentes.

\section{Resultados}

Foram identificados 27 estudos, dentre os quais nove foram excluídos por não cumprirem os critérios de seleção (Figura 1). Dos 18 selecionados, apenas um era em língua espanhola, sendo os demais em inglês. Foi possível obter todos os 18 artigos completos disponíveis em formato eletrônico por meio do acesso a portais cadastrados.
Na Tabela 1, estão descritas as características gerais dos estudos revisados. A maioria das publicações se concentrou entre 2003 e 2005, sendo a mais antiga publicada em 1998. A maior parte foi publicada em revistas inglesas: Social Science and Medicine (6) e Journal of Epidemiology and Community Health (5). Oito investigações foram realizadas nos Estados Unidos, sendo três elaboradas pelo mesmo grupo de autores, na cidade de Chicago, e quatro relativas a todo o país, com pelo menos dois autores em comum. Um autor em comum com este último grupo aparece em outros dois artigos sobre o Chile. Os dois artigos na Escócia e Inglaterra foram realizados por um mesmo grupo de autores. Além desses, houve dois artigos realizados no Canadá, um na Holanda, um na Alemanha, um na Suécia e um na Rússia.

A principal fonte de informações sobre auto-avaliação de saúde foram pesquisas nacionais sobre saúde, utilizadas em 12 artigos; a seguir, encontram-se pesquisas municipais (4), uma pesquisa postal específica para a costa da Colúmbia Britânica, no Canadá, e uma para a população hispânica idosa em estados do sudoeste americano. Em 14 estudos, as respostas à questão sobre auto-avaliação de saúde foram dicotomizadas (definição de duas categorias originadas de combinações entre as opções de resposta que entre os estudos variaram entre 4,5 ou 6 categorias), no formato de saúde boa versus saúde ruim, outros quatro a analisaram como variável ordinal (de 4 ou 5 categorias).

As fontes de informação mais utilizadas para dados sobre características de contexto foram os censos demográficos e outras pesquisas populacionais. Além destas, outras fontes como estatísticas de mercado, impostos, sistemas de informação sobre mortalidade, e dados de institutos e organizações não governamentais, também foram utilizadas.

Em 15 dos artigos, o nível individual de classe social ou situação sócio-econômica foi medido por mais de uma variável. As mais freqüentes foram escolaridade e renda, seguidas de classe social e situação de emprego. Além de sexo, idade e raça/etnia, variáveis relacionadas a condições e hábitos de saúde, situação conjugal e outros fatores sociais também foram consideradas.

\section{Unidades espaciais analisadas para a seleção das características de contexto e da vizinhança}

As unidades espaciais de análise do nível contextual variaram desde setores censitários até estados. Áreas geográficas pequenas como setores censitários e distritos foram utilizadas para repre- 


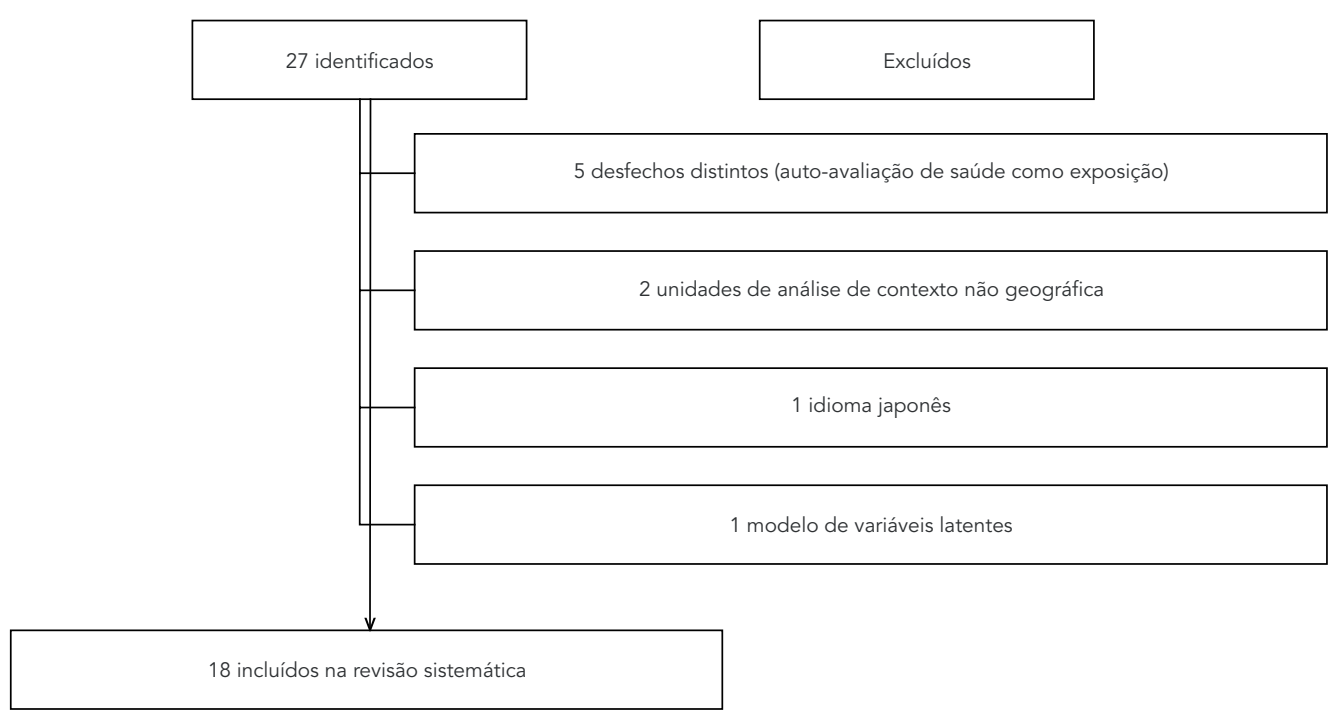

sentar cidades. Quando agregadas em conjuntos de setores, foram denominadas de vizinhança. Somente em um artigo os setores censitários representavam estados 30 . As pequenas áreas de mercado (menores unidades de área num sistema de coordenadas geográficas que cobre todo o país) na Suécia foram utilizadas para representar o país, assim como as quadras do correio, na Escócia e Inglaterra. Além disso, como subunidades representando todo o país, foram utilizadas comunidades (no Chile), cidades, estados e regiões (na Rússia).

As unidades espaciais de análise denominadas de vizinhança foram os setores censitários e suas agregações, as áreas de correio e a vizinhança de cidades alemãs, todas baseadas em recortes político-administrativos. Somente os estudos do Projeto de Desenvolvimento Humano e das Vizinhanças de Chicago (PHDCN) utilizaram vizinhanças delimitadas especificamente para a pesquisa de processos sociais. Neste caso, as vizinhanças foram criadas mediante agrupamentos de setores censitários, de acordo com critérios que as tornassem mais ecologicamente significativas, compostas por setores censitários contíguos e internamente homogêneos segundo os indicadores-chave do censo (por exemplo, sócio-econômicos e composição racial) 31. O entrevistado, ao ser questionado sobre características da sua vizinhança, era esclarecido de que por vizinhança entendia-se " $a$ área do entorno onde vivia e ao redor da sua casa, podendo incluir lugares para fazer compras, instituições religiosas ou públicas, ou distritos locais de negócios. É a área geral do entorno da residência onde o participante costuma realizar atividades de rotina, como compras, idas ao parque, ou visitar vizinhos" 25 (p. 638).

\section{Resultados encontrados para a associação entre características da vizinhança e auto-avaliação de saúde}

A síntese descritiva das características dos estudos é apresentada de acordo com a escala geográfica utilizada no conjunto de Tabelas 2, 3, 4 e 5. De acordo com os resultados de 15 dentre os 18 estudos revisados, houve associação significativa entre, pelo menos, uma medida de características de vizinhança e auto-avaliação de saúde.

A escala de cidade foi escolhida para o estudo das características de contexto em cinco artigos (Tabela 2).

No estudo realizado em Amsterdã 33 foram analisados indicadores de carência sócio-econômica (baixa renda e desemprego) em nível distrital. A prevalência de saúde ruim, ajustada por idade e sexo, foi maior em áreas urbanas mais carentes. As diferenças foram explicadas pela presença de maior número de residentes com piores 
Tabela 1

Autor(es), periódicos, fontes de dados e local de estudos de efeitos multinível na auto-avaliação de saúde, 2005.

\begin{tabular}{|c|c|c|c|c|c|}
\hline \multirow[t]{2}{*}{ Referência } & \multirow[t]{2}{*}{ Ano } & \multirow[t]{2}{*}{ Periódico } & \multirow[t]{2}{*}{ Local do estudo } & \multicolumn{2}{|c|}{ Fonte de dados } \\
\hline & & & & $\begin{array}{c}\text { Desfecho } \\
\text { (auto-avaliação de saúde) }\end{array}$ & $\begin{array}{c}\text { Exposição } \\
\text { (características de contexto) }\end{array}$ \\
\hline Reijneveld 32 & 1998 & Int J Epidemiol & $\begin{array}{l}\text { Amsterdã } \\
\text { (Holanda) }\end{array}$ & Pesquisa municipal, 1992-1993 & $\begin{array}{l}\text { Documentos de taxação de } \\
\text { impostos, } 1989\end{array}$ \\
\hline Malmtröm et al. 17 & 1999 & AJPH & Suécia & $\begin{array}{l}\text { Swedish Annual Level of Living } \\
\text { Survey, 1988-1989 }\end{array}$ & Market Statisctics, 1990-1992 \\
\hline Subramanian et al. 41 & 2001 & Soc Sci Med & Estados Unidos & $\begin{array}{l}\text { Behavioral Risk Factor } \\
\text { Surveillance System, 1993-1994 }\end{array}$ & $\begin{array}{l}\text { Populational Survey, 1990-1992 } \\
\text { General Social Survey, 1986-1990 }\end{array}$ \\
\hline Reijneveld 33 & 2002 & $\begin{array}{l}J \text { Epidemiol Community } \\
\text { Health }\end{array}$ & Alemanha & $\begin{array}{l}\text { Health Interview Surveys, 1991- } \\
2000\end{array}$ & Netherlands Statistics, 1995 \\
\hline Subramanian et al. 43 & 2002 & J Urban Health & Estados Unidos & $\begin{array}{l}\text { Social Capital Community } \\
\text { Benmchmark Survey, } 2000\end{array}$ & $\begin{array}{l}\text { Social Capital Community } \\
\text { Benmchmark Survey, } 2000\end{array}$ \\
\hline Subramanian et al. 45 & 2003 & Rev Méd Chile & Chile & $\begin{array}{l}\text { National Socio Economic } \\
\text { Characterization Survey, } 2000\end{array}$ & $\begin{array}{l}\text { National Socio Economic } \\
\text { Characterization Survey, } 2000\end{array}$ \\
\hline Browning et al. 34 & 2003 & Soc Sci Med & $\begin{array}{l}\text { Chicago } \\
\text { (Estados Unidos) }\end{array}$ & $\begin{array}{l}\text { Project of Human Development } \\
\text { in Chicago Neighborhoods- } \\
\text { Community Survey, } 1995\end{array}$ & United States Census, 1990 \\
\hline Wen et al. 12 & 2003 & Soc Sci Med & $\begin{array}{l}\text { Chicago } \\
\text { (Estados Unidos) }\end{array}$ & $\begin{array}{l}\text { Project of Human Development } \\
\text { in Chicago Neighborhoods- } \\
\text { Community Survey, } 1995\end{array}$ & $\begin{array}{l}\text { United States Census, } 1990 \\
\text { Metropolitan Chicago } \\
\text { Information Center-Metro Survey, } \\
\text { 1992-1994 } \\
\text { Project of Human Development } \\
\text { in Chicago Neighborhoods- } \\
\text { Community Survey, } 1995 \\
\text { Homicide, 1991-1993 }\end{array}$ \\
\hline Subramanian et al. 46 & 2003 & $\begin{array}{l}J \text { Epidemiol Community } \\
\text { Health }\end{array}$ & Chile & $\begin{array}{l}\text { National Socio Economic } \\
\text { Characterization Survey, } 2000\end{array}$ & $\begin{array}{l}\text { National Socio Economic } \\
\text { Characterization Survey, } 2000\end{array}$ \\
\hline Patel 30 & 2003 & Ann Epidemiol & $\begin{array}{l}\text { Estados do } \\
\text { sudoeste dos } \\
\text { Estados Unidos }\end{array}$ & $\begin{array}{l}\text { Hispanic Stablished Population } \\
\text { for the Epidemiological Study of } \\
\text { the Elderly }\end{array}$ & United States Census, 1990 \\
\hline Jun et al. 42 & 2004 & $\begin{array}{l}\text { J Am Med Womens } \\
\text { Assoc }\end{array}$ & Estados Unidos & $\begin{array}{l}\text { Behavioral Risk Factor } \\
\text { Surveillance System, } 2000\end{array}$ & $\begin{array}{l}\text { Current Population Survey (CPS), } \\
\text { 1999, } 2000 \text { e } 2001 \\
\text { Economic Police Institute and } \\
\text { Center on Budget and Police } \\
\text { Priorities, 1996-1998 } \\
\text { The Status of Women in the } \\
\text { States, } 2000\end{array}$ \\
\hline Hou \& Myles 36 & 2005 & Soc Sci Med & Canadá & $\begin{array}{l}\text { National Population Health } \\
\text { Survey, 1996-1997 }\end{array}$ & $\begin{array}{l}\text { Canada's Census Metropolitan } \\
\text { Areas, } 1996\end{array}$ \\
\hline
\end{tabular}

(continua) 


\begin{tabular}{|c|c|c|c|c|c|}
\hline \multirow[t]{2}{*}{ Referência } & \multirow[t]{2}{*}{ Ano } & \multirow[t]{2}{*}{ Periódico } & \multirow[t]{2}{*}{ Local do estudo } & \multicolumn{2}{|c|}{ Fonte de dados } \\
\hline & & & & $\begin{array}{c}\text { Desfecho } \\
\text { (auto-avaliação de saúde) }\end{array}$ & $\begin{array}{c}\text { Exposição } \\
\text { (características de contexto) }\end{array}$ \\
\hline Stafford et al. 38 & 2005 & Soc Sci Med & $\begin{array}{l}\text { Inglaterra e } \\
\text { Escócia } \\
\text { (Reino Unido) }\end{array}$ & $\begin{array}{l}\text { Health Survey for England, } \\
\text { 1994-1999 } \\
\text { Scottish Health Survey, } \\
\text { 1995-1998 }\end{array}$ & $\begin{array}{l}\text { Health Survey for England, } \\
\text { 1994-1999 } \\
\text { Scottish Health Survey, } \\
\text { 1995-1998 } \\
\text { Coesão social para questionário } \\
\text { postal }\end{array}$ \\
\hline Cummins et al. 39 & 2005 & $\begin{array}{l}J \text { Epidemiol Community } \\
\text { Health }\end{array}$ & $\begin{array}{l}\text { Inglaterra e } \\
\text { Escócia } \\
\text { (Reino Unido) }\end{array}$ & $\begin{array}{l}\text { Health Survey for England, } \\
\text { 1994-1999 } \\
\text { Scottish Health Survey, } \\
\text { 1995-1998 }\end{array}$ & $\begin{array}{l}\text { Health Survey for England, } \\
\text { 1994-1999 } \\
\text { Scottish Health Survey, } \\
\text { 1995-1998 } \\
\text { Coesão social para questionário } \\
\text { postal }\end{array}$ \\
\hline Veenstra 37 & 2005 & Soc Sci Med & $\begin{array}{l}\text { Colúmbia Britânica } \\
\text { (Canadá) }\end{array}$ & Mailed Survey, 2002 & Mailed Survey, 2002 \\
\hline Carlson 40 & 2005 & $\begin{array}{l}J \text { Epidemiol Community } \\
\text { Health }\end{array}$ & Rússia & $\begin{array}{l}\text { Russian Longitudinal } \\
\text { Monitoring Survey, } 1998\end{array}$ & $\begin{array}{l}\text { Russian Longitudinal Monitoring } \\
\text { Survey, } 1998\end{array}$ \\
\hline Cagney et al. 35 & 2005 & $\begin{array}{l}\text { J Gerontol B Psychol Sci } \\
\text { Soc Sci }\end{array}$ & $\begin{array}{l}\text { Chicago (Estados } \\
\text { Unidos) }\end{array}$ & $\begin{array}{l}\text { Metropolitan Chicago } \\
\text { Information Center-Metro } \\
\text { Survey, 1991-2000 }\end{array}$ & $\begin{array}{l}\text { United States Census, } 1990 \\
\text { Project of Human Development } \\
\text { in Chicago Neighborhoods- } \\
\text { Community Survey, 1994-1995 }\end{array}$ \\
\hline Subramanian et al. 44 & 2005 & $\begin{array}{l}J \text { Epidemiol Community } \\
\text { Health }\end{array}$ & Estados Unidos & $\begin{array}{l}\text { Social Capital Community } \\
\text { Benchmark Survey, } 2000\end{array}$ & $\begin{array}{l}\text { Social Capital Community } \\
\text { Benchmark Survey, } 2000\end{array}$ \\
\hline
\end{tabular}

indicadores sócio-econômicos individuais nas áreas mais carentes, ou seja, pela composição das áreas e não por um efeito contextual.

Em outro estudo do mesmo autor, realizado em sete cidades alemãs 33 , as diferenças de efeito sócio-econômico do nível de vizinhança na auto-avaliação de saúde foram encontradas em todas as grandes cidades estudadas. A chance de avaliar a saúde como ruim foi $33 \%$ maior (odds ratio - OR = 1,33; intervalo de $95 \%$ de confiança - IC95\%: 1,21-1,44) na presença de carência (índice General Practitioner), $60 \%$ maior ( $\mathrm{OR}=1,60$; IC95\%: 1,47-1,73) para renda média desfavorável e $52 \%$ maior $(\mathrm{OR}=1,52$; IC95\%: 1,40-1,65) para proporção desfavorável de benefício social, após ajuste para variáveis individuais e cidade de residência.

No primeiro estudo das vizinhanças de Chicago 34 , os resultados indicaram que a riqueza exerce um efeito protetor contra a avaliação da saúde como ruim, a cada $10 \%$ de aumento na riqueza da vizinhança ocorre redução de $10 \%$ da chance de saúde ruim no nível individual. No entanto o nível de pobreza da vizinhança não contribuiu significativamente para explicar a variação da auto-avaliação de saúde.

No segundo estudo de Chicago 12, além de analisar as influências da estrutura econômica da vizinhança na saúde individual, os autores exploraram o ambiente físico, os serviços de saúde, problemas sociais (homicídio) e os recursos sociais disponíveis como mecanismos que operam no nível de vizinhança e que podem explicar a influência das condições sócio-econômicas estruturais sobre a saúde. Os resultados indicaram que a riqueza exerce efeitos contextuais significativos na auto-avaliação de saúde, enquanto a pobreza e a desigualdade de renda (coeficiente de Gini) não foram importantes no nível de vizinhança. A pobreza da vizinhança não exerce efeito contextual com ou sem a presença de outras medidas sócio-econômicas da vizinhança. A concentração de riqueza está positivamente associada com a auto-avaliação de saúde e, no 
Síntese descritiva dos estudos multinível para efeitos de contexto na auto-avaliação de saúde para cidades, 2005.

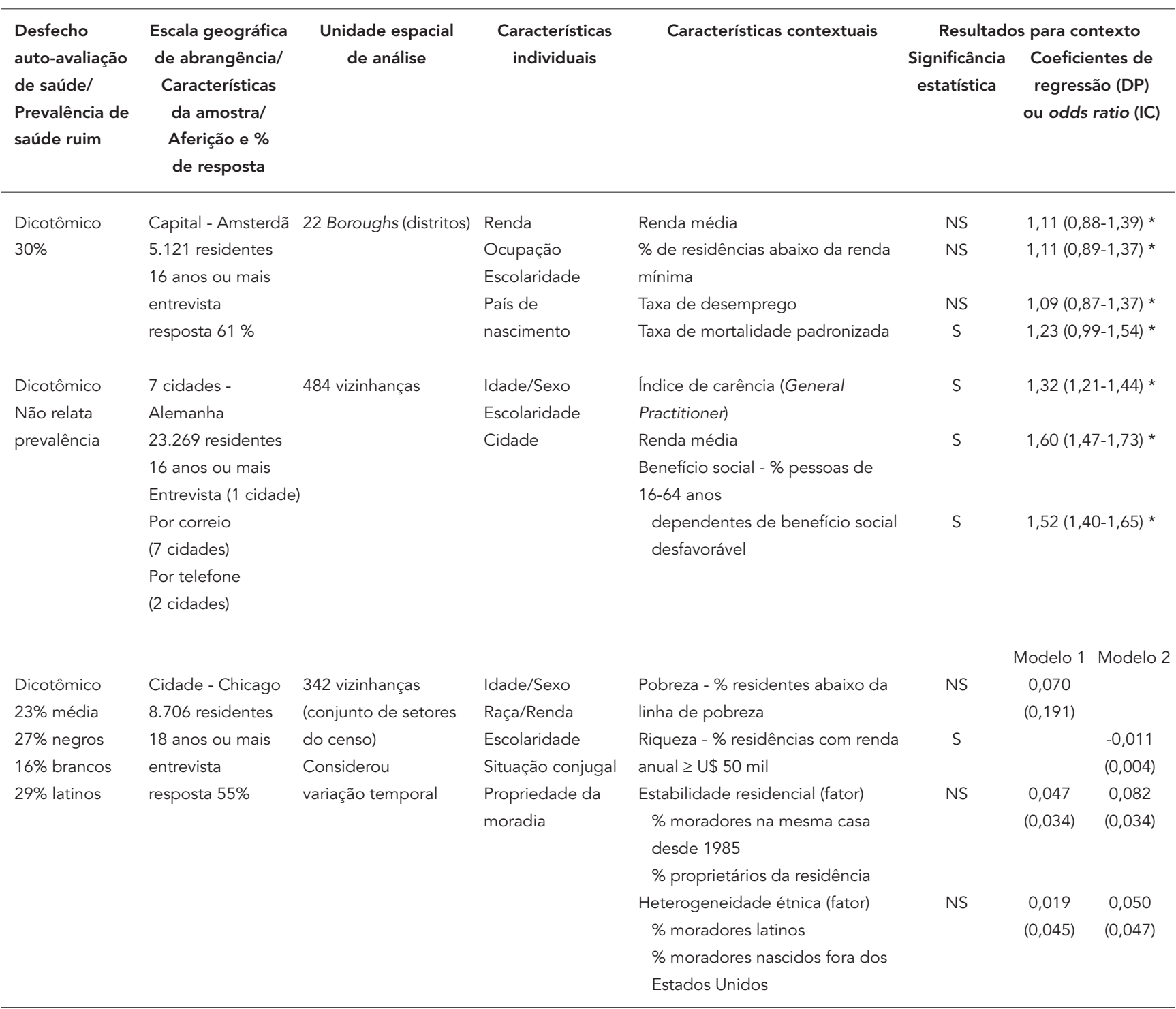

(continua)

nível de vizinhança, tem maior poder de afetar a saúde do que a pobreza ou a desigualdade de renda. Quanto mais alto o nível de escolaridade da vizinhança, maior a chance de auto-avaliação de saúde melhor. Os resultados relativos às medidas de eficácia social, baseadas em quatro componentes do capital social (reciprocidade, densidade de rede social local, coesão social e controle social informal) sugerem que os recursos sociais no nível de vizinhança são determinantes mais poderosos da auto-avaliação de saúde do que a disponibilidade de serviços de saúde e também do que a exposição a homicídios. $\mathrm{O}$ ambiente físico ou o nível de desordem física na vizinhança media o efeito da riqueza na autoavaliação de saúde, em menor grau do que os recursos sociais.

É importante observar que, segundo esses estudos 12,34, o nível individual de renda tem um efeito consideravelmente maior na auto-avaliação de saúde que a riqueza da vizinhança. Assim, a pobreza no nível individual afeta negativamente a saúde, mesmo com o potencial benefício vinculado ao fato de morar em vizinhanças com maior riqueza.

No terceiro estudo de Chicago 35 , a população estudada se restringiu às pessoas com mais de 55 anos de idade, com o objetivo de estudar o im- 
Tabela 2 (continuação)

\begin{tabular}{|c|c|c|c|c|c|c|c|}
\hline \multirow{6}{*}{$\begin{array}{l}\text { Desfecho } \\
\text { auto-avaliação } \\
\text { de saúde/ } \\
\text { Prevalência de } \\
\text { saúde ruim }\end{array}$} & \multirow{6}{*}{$\begin{array}{c}\text { Escala geográfica } \\
\text { de abrangência/ } \\
\text { Características } \\
\text { da amostra / } \\
\text { Aferição e \% } \\
\text { de resposta }\end{array}$} & \multirow{6}{*}{$\begin{array}{l}\text { Unidade espacial } \\
\text { de análise }\end{array}$} & \multirow{6}{*}{$\begin{array}{c}\text { Características } \\
\text { individuais }\end{array}$} & \multirow[t]{6}{*}{ Características contextuais } & \multicolumn{3}{|c|}{ Resultados para contexto } \\
\hline & & & & & \multirow{5}{*}{$\begin{array}{c}\text { Significância } \\
\text { estatística }\end{array}$} & \multirow{3}{*}{\multicolumn{2}{|c|}{$\begin{array}{l}\text { Coeficientes de } \\
\text { regressão (DP) } \\
\text { ou odds ratio (IC) }\end{array}$}} \\
\hline & & & & & & & \\
\hline & & & & & & & \\
\hline & & & & & & & \\
\hline & & & & & & & \\
\hline & & & & & \multicolumn{3}{|c|}{ Modelo 1 Modelo 2} \\
\hline Ordinal (4) & Cidade - Chicago & 275 de 343 vi- & Idade/Sexo & Condição prévia de saúde (auto- & NS & $-0,029$ & $-0,054$ \\
\hline Ruim 4 \% & 8.782 e 3.459 & zinhanças (conjunto & Raça-etnia/Renda & avaliação de saúde prévia) & & & \\
\hline Regular $18 \%$ & residentes & de setores do censo) & Escolaridade & Pobreza - \% residentes abaixo da & NS & 0,399 & 0,664 \\
\hline Boa $44 \%$ & 18 anos ou mais & & Situação conjugal & linha de pobreza & & & \\
\hline Excelente 34\% & entrevista & & Hábito de fumar & Coeficiente de Gini & NS & 0,380 & 0,909 \\
\hline \multirow[t]{22}{*}{ (Dicotômico) } & resposta $75 \%$ e & & Hipertensão & Riqueza - \% residências c/renda & $\mathrm{S}$ & 1,612 & (NS) 0,676 \\
\hline & $55 \%$ & & arterial sistêmica & anual $\geq \cup \$ 50 \mathrm{mil}$ & & & \\
\hline & & & Ano da pesquisa & Nível de escolaridade - \% & $\mathrm{S}$ & 4,122 & 3,542 \\
\hline & & & & residentes com curso superior & & & \\
\hline & & & & Desordem no ambiente físico & $\mathrm{S}$ & & 0,127 \\
\hline & & & & Garrafas quebradas ou lixo nas & & & \\
\hline & & & & calçadas ou ruas & & & \\
\hline & & & & Pichações nas paredes e nos & & & \\
\hline & & & & imóveis & & & \\
\hline & & & & Casas ou lojas vazias ou & & & \\
\hline & & & & abandonadas & & & \\
\hline & & & & Adequação serviços de saúde & & & \\
\hline & & & & locais & NS & & $-0,114$ \\
\hline & & & & Serviço de saúde da família & & & \\
\hline & & & & Serviço de aconselhamento para & & & \\
\hline & & & & crianças e adolescentes & & & \\
\hline & & & & Programa de tratamento para & & & \\
\hline & & & & dependência química & & & \\
\hline & & & & Centro de saúde mental & & & \\
\hline & & & & Exposição ao crime - taxa de & $\mathrm{N}$ & $-0,121$ & $-0,091$ \\
\hline & & & & homicídios & & & \\
\hline & & & & Eficácia coletiva (escala de 7 itens) & $\mathrm{S}$ & 0,183 & 0,171 \\
\hline Dicotômico & Cidade - Chicago & 246 vizinhanças & Idade/Sexo & Pobreza - \% residentes abaixo da & NS & & \\
\hline $45 \%$ negros & 656 residentes & (conjunto setores do & Raça-etnia/Renda & linha de pobreza & & & \\
\hline \multirow[t]{14}{*}{$27 \%$ brancos } & 55 anos ou mais & censo) & Escolaridade & Riqueza - \% residências c/renda & $\mathrm{S}$ & \multicolumn{2}{|c|}{$-0,024$} \\
\hline & entrevista & & Situação conjugal & anual $\geq \cup \$ 50 \mathrm{mil}$ & & \multicolumn{2}{|c|}{$(0,008)$} \\
\hline & resposta $55 \%$ & & Atividade física & Estabilidade residencial (fator) & $\mathrm{S}$ & \multicolumn{2}{|c|}{0,276} \\
\hline & & & Problemas com o & $\%$ moradores na mesma casa & & \multirow{2}{*}{\multicolumn{2}{|c|}{$(0,091)$}} \\
\hline & & & peso & desde 1985 & & & \\
\hline & & & Ano da pesquisa & \% proprietários da residência & & & \\
\hline & & & & Estrutura etária - \% com 55 anos & NS & \multicolumn{2}{|c|}{0,010} \\
\hline & & & & ou mais & & \multicolumn{2}{|c|}{$(0,011)$} \\
\hline & & & & Eficácia coletiva & NS & \multicolumn{2}{|c|}{$-0,012$} \\
\hline & & & & & & \multicolumn{2}{|c|}{$(0,097)$} \\
\hline & & & & Coesão social (escala 5 pontos) & & \multicolumn{2}{|c|}{$-0,011$} \\
\hline & & & & & & $(0$, & 006) \\
\hline & & & & Controle social Informal (2 itens) & & -0 , & 024 \\
\hline & & & & & & $(0$, & 008) \\
\hline
\end{tabular}

S: significativo; NS: não significativo.

* Valores referentes ao odds ratio (IC). 
pacto da vizinhança nos conhecidos diferenciais raciais da auto-avaliação de saúde. Os resultados indicaram que a riqueza da vizinhança contribui positivamente para a melhor auto-avaliação de saúde e atenua os diferenciais de associação entre raça e auto-avaliação de saúde. Quando o nível de riqueza na comunidade é baixo, a estabilidade residencial é negativamente relacionada à saúde. Segundo esta investigação, a eficácia coletiva como medida de recursos sociais da vizinhança não esteve associada à saúde da população idosa.

A comparação entre os resultados destes estudos sugere que, provavelmente, a unidade espacial de análise de vizinhança é mais apropriada para os estudos intra-urbanos do que os distritos, uma vez que houve melhor discriminação dos efeitos de contexto com recortes territoriais de áreas menores.

Três artigos utilizaram a escala de estados ou regiões para estudar a influência das características de contexto na auto-avaliação de saúde (Tabela 3).

Para determinar características de vizinhança associadas com a auto-avaliação de saúde em idosos americano-mexicanos 30 , uma amostra de moradores de cinco estados da fronteira Estados Unidos/México foi pesquisada. Os autores relataram que após ajustar para características individuais, os idosos americano-mexicanos apresentaram tendência de avaliar pior a sua saúde quando moravam em vizinhanças com desvantagem sócio-econômica (OR = 1,31; IC95\%: 1,11$1,55)$, ou localizadas dentro da faixa de fronteira (OR = 1,53; IC95\%: 1,17-2,00). A maior homogeneidade étnica (proporção de moradores americano-mexicanos) reduz a chance de auto-avaliação de saúde ruim (OR = 0,92; IC95\%: 0,85-0,98). Aproximadamente $16 \%$ da variação da auto-avaliação de saúde foram em razão da variação entre vizinhanças, e 40,3\% desta foi explicada pelo nível econômico da vizinhança, composição étnica e distância da fronteira.

No estudo de 25 áreas metropolitanas no Canadá 36 , os autores avaliaram a contribuição da desigualdade de renda da vizinhança no impacto dos níveis de renda (pobreza/riqueza) da vizinhança na auto-avaliação de saúde, independentemente do nível individual de recursos sócio-econômicos. Os resultados indicaram que a relação "ecológica" negativa entre a desigualdade de renda da vizinhança e a média da auto-avaliação de saúde da vizinhança, resulta não só de diferenças de composição entre os indivíduos, mas também de efeitos contextuais dos níveis de renda da vizinhança. A chance de referir melhor saúde foi cerca de $15 \%$ maior entre indivíduos que viviam em vizinhanças com menor desigualdade, comparados àqueles que viviam em vizinhanças com alta e média desigualdade. O nível de renda da vizinhança apresentou associação positiva e independente com a auto-avaliação de saúde, para além dos efeitos do nível sócio-econômico individual e características relacionadas. Indivíduos que viviam em vizinhanças de alta renda apresentaram chance $47 \%$ a $50 \%$ maior de referir melhor saúde do que aqueles de vizinhanças de baixa renda. Os autores concluíram que a desigualdade da vizinhança reflete condições sócio-econômicas (por exemplo, boa educação dos residentes) que não são completamente capturadas nem pela renda média da vizinhança nem pelas características individuais.

O estudo de Veenstra 37 pretendia avaliar a proporção da variabilidade da saúde individual que pudesse ser atribuída à comunidade e também estabelecer as funções específicas do capital social, riqueza da comunidade (community wealth) e desigualdade de renda como preditores da auto-avaliação de saúde. Utilizando análise multinível, nenhuma variação da auto-avaliação de saúde pôde ser atribuída à comunidade, e o autor se restringiu a discutir os resultados em um modelo multivariado individual. Ressaltem-se as observações do autor sobre as limitações desse estudo, já que a taxa de reposta de apenas $56,5 \%$, apesar de respeitável para uma pesquisa postal do público em geral, é baixa para propósitos de inferência estatística, implicando baixo poder do estudo para detectar associações como significantes. Adicionalmente, o fato de a amostra ter sido selecionada com base numa lista telefônica pode ter acarretado vieses de seleção.

Três estudos cuja escala foram países utilizaram unidades espaciais de análise de pequenas áreas (Tabela 4).

No estudo da Suécia 17, os autores analisaram a associação dos índices Care Need Index (CNI) e Towsend de vizinhanças com a auto-avaliação de saúde, ajustada por idade, sexo, escolaridade, índice de massa corporal (IMC), fumo e atividade física. De acordo com os resultados, quanto maior a carência da vizinhança, pior a auto-avaliação de saúde para todos os níveis de escolaridade. Participantes que moravam nas vizinhanças mais carentes (CNI mais alto) apresentaram chance $89 \%$ maior de avaliarem sua saúde como ruim $(\mathrm{OR}=1,89$; IC95\%: $1,52-2,22)$ do que aqueles que viviam nas áreas menos carentes.

No primeiro estudo do Reino Unido (Inglaterra e Escócia) 38, os autores investigaram diferenças de aspectos do ambiente residencial na auto-avaliação de saúde de homens e mulheres, em separado. Aspectos físicos e sócio-políticos do ambiente assim como características econô- 
Síntese descritiva dos estudos multinível para efeitos de contexto na auto-avaliação de saúde, para estados e regiões, 2005.

\begin{tabular}{|c|c|c|c|c|c|c|}
\hline \multirow{3}{*}{$\begin{array}{l}\text { Desfecho } \\
\text { auto-avaliação } \\
\text { de saúde/ } \\
\text { Prevalência de } \\
\text { saúde ruim }\end{array}$} & \multirow{3}{*}{$\begin{array}{l}\text { Escala geográfica } \\
\text { de abrangência/ } \\
\text { Características } \\
\text { da amostra/ } \\
\text { Aferição e \% } \\
\text { de resposta }\end{array}$} & \multirow{3}{*}{$\begin{array}{l}\text { Unidade espacial } \\
\text { de análise }\end{array}$} & \multirow{3}{*}{$\begin{array}{l}\text { Características } \\
\text { individuais }\end{array}$} & \multirow[t]{3}{*}{ Características contextuais } & \multicolumn{2}{|c|}{ Resultados para contexto } \\
\hline & & & & & $\begin{array}{l}\text { Significância } \\
\text { estatística }\end{array}$ & $\begin{array}{l}\text { Coeficientes de } \\
\text { regressão (DP) }\end{array}$ \\
\hline & & & & & & ou odds ratio (IC) \\
\hline Ordinal (4) & 5 estados do & 210 setores & Idade/Sexo/Situação & Índice de desvantagem sócio- & $\mathrm{S}$ & $1,31(1,11-1,55)$ * \\
\hline Ruim $16 \%$ & sudoeste dos & censitários & conjugal & econômica & & \\
\hline Pobre 44\% & Estados Unidos & (vizinhanças) & Renda total anual & 1. Fator econômico & & \\
\hline Boa $28 \%$ & 3.050 idosos & & Escolaridade & Emprego, tipo de renda, pobreza & & \\
\hline Excelente $12 \%$ & americano- & & Fatores sociais & (6 indicadores) & & \\
\hline \multirow[t]{11}{*}{ (Dicotômico) } & mexicanos & & Aculturação & 2. Fator educação/ocupação & & \\
\hline & 65 anos ou mais & & média & Educação, classe ocupacional & & \\
\hline & Entrevista & & Financial strain & Homogeneidade étnica (\% de & $\mathrm{S}$ & $0,92(0,85-0,98)$ * \\
\hline & & & Apoio social médio & americo-mexicanos) & & \\
\hline & Resposta 83\% & & Média de eventos & Proximidade da fronteira Estados & $\mathrm{S}$ & $1,53(1,17-2,00)$ * \\
\hline & & & estressores & Unidos/México & & \\
\hline & & & Hábitos de saúde & & & \\
\hline & & & IMC/Fumo/ & & & \\
\hline & & & Deficiência/ & & & \\
\hline & & & Problemas prévios & & & \\
\hline & & & de saúde & & & \\
\hline Ordinal (5) & 25 áreas & 61 setores & Idade/Sexo & Desigualdade de renda (6 medidas & NS & \\
\hline Pobre 2\% & metropolitanas & censitários & Status minoria racial & agrupadas) & & \\
\hline Ruim 7\% & do Canadá & & Renda familiar & Renda média & $\mathrm{S}$ & \\
\hline Boa $27 \%$ & 34.613 residentes & & Status de migração & Mean Log deviation & $\mathrm{S}$ & $0,295(0,050)$ \\
\hline Muito boa $38 \%$ & 12 anos ou mais & Cidades & & Índice de Theil & $\mathrm{S}$ & $0,283(0,048)$ \\
\hline Excelente $26 \%$ & entrevista & & & Coeficiente de Gini & $\mathrm{S}$ & $0,271(0,051)$ \\
\hline \multirow[t]{8}{*}{ (Dicotômico) } & & & & $\begin{array}{l}\text { Median Share, } \% \text { da renda com } \\
\text { os } 50 \% \text { mais ricos }\end{array}$ & $\mathrm{S}$ & $0,248(0,054)$ \\
\hline & & & & Coeficiente de Variação ao & $\mathrm{S}$ & $0,293(0,045)$ \\
\hline & & & & Quadrado & & \\
\hline & & & & $\begin{array}{l}\text { Educação, \% de maiores de } 15 \\
\text { anos com grau universitário }\end{array}$ & $\mathrm{S}$ & \\
\hline & & & & $\begin{array}{l}\text { Idade, \% de adultos com mais de } \\
65 \text { anos }\end{array}$ & NS & \\
\hline & & & & $\begin{array}{l}\text { Família, \% de famílias com single } \\
\text { parent }\end{array}$ & $\mathrm{S}$ & \\
\hline & & & & $\begin{array}{l}\text { Imigração, \% de imigrantes há } \\
\text { menos de } 10 \text { anos }\end{array}$ & NS & \\
\hline & & & & Raça, \% de não brancos & NS & \\
\hline
\end{tabular}

(continua) 


\begin{tabular}{|c|c|c|c|c|c|c|}
\hline \multirow{6}{*}{$\begin{array}{l}\text { Desfecho } \\
\text { auto-avaliação } \\
\text { de saúde/ } \\
\text { Prevalência de } \\
\text { saúde ruim }\end{array}$} & \multirow{6}{*}{$\begin{array}{l}\text { Escala geográfica } \\
\text { de abrangência/ } \\
\text { Características } \\
\text { da amostra / } \\
\text { Aferição e \% } \\
\text { de resposta }\end{array}$} & \multirow{6}{*}{$\begin{array}{l}\text { Unidade espacial } \\
\text { de análise }\end{array}$} & \multirow{6}{*}{$\begin{array}{c}\text { Características } \\
\text { individuais }\end{array}$} & \multirow[t]{6}{*}{ Características contextuais } & \multicolumn{2}{|c|}{ Resultados para contexto } \\
\hline & & & & & Significância & Coeficientes de \\
\hline & & & & & estatística & regressão (DP) \\
\hline & & & & & & ou odds ratio (IC) \\
\hline & & & & & & \\
\hline & & & & & & \\
\hline \multirow{14}{*}{$\begin{array}{l}\text { Dicotômico } \\
13 \%\end{array}$} & Colúmbia & 25 comu- & Ano de nascimento & Capital social (escala) & EANS & \\
\hline & Britânica, & nidades & Renda & Número de espaços públicos per & & \\
\hline & Canadá & & Escolaridade & capita & & \\
\hline & 1.435 residentes & & Confiança social & Número de organizações & & \\
\hline & 18 anos ou mais & & Confiança política & voluntárias per capita & & \\
\hline & Questinário postal & & Participação em & Agregação de escalas individuais & & \\
\hline & Resposta $56,5 \%$ & & associações & Níveis médios de confiança & & \\
\hline & & & de voluntariado & política & & \\
\hline & & & & Níveis médios de confiança & & \\
\hline & & & & comunitária & & \\
\hline & & & & Renda média das residências & & \\
\hline & & & & Desigualdade de renda - \% total & & \\
\hline & & & & da renda possuída pelos $50 \%$ mais & & \\
\hline & & & & 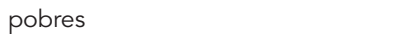 & & \\
\hline
\end{tabular}

S: significativo; NS: não significativo; EANS: efeito aleatório do nível de contexto não significativo; IMC: índice de massa corporal.

* Valores referentes ao odds ratio (IC).

micas individuais apresentaram-se consistentemente relacionadas à auto-avaliação de saúde das mulheres. Por outro lado, a situação de emprego individual esteve mais fortemente ligada à auto-avaliação de saúde dos homens.

No segundo estudo ${ }^{39}$, os autores mostraram que a auto-avaliação de saúde ruim esteve significativamente associada a seis atributos da vizinhança: baixa qualidade do ambiente residencial, orientação política dos representantes eleitos; baixo engajamento político, alto desemprego, baixo acesso ao transporte privado e baixa presença de automóveis de maior valor. Essas associações foram independentes de sexo, idade, classe social e atividade econômica. As razões de chance foram maiores para indivíduos desempregados do que empregados. As outras cinco medidas de vizinhança: recreação pública, crime, oferta de serviços de saúde, acesso a lojas de alimentos e a bancos e escritórios não apresentaram associação com a auto-avaliação de saúde.

Sete artigos apresentaram unidades espaciais de análise com grandes áreas geográficas (regiões, estados e comunidades) para o estudo de países (Tabela 5).

O estudo de desigualdades de renda nas regiões da Rússia 40 mostrou que os diferenciais regionais da auto-avaliação de saúde entre homens foram explicados parcialmente pelas diferenças de renda das regiões, enquanto para as mulheres, as características individuais como idade e nível educacional foram mais importantes. O autor destaca que a amostra estudada foi planejada para representar a população nacional e que pode não ser representativa para as regiões. Desse modo, os resultados devem ser vistos com cautela.

No artigo sobre desigualdades de renda em 39 estados norte-americanos 41, efeitos contextuais entre estados foram encontrados para renda média per capita e capital social. Apesar de não muito forte, parece ter havido impacto diferencial da desigualdade de renda em nível estadual nos grupos de alta renda. Indivíduos de alta renda que vivem em estados com maior desigualdade têm probabilidade menor de relatar saúde ruim.

Em outro estudo, realizado em 50 estados norte-americanos 42 , vários índices compostos de status feminino foram utilizados para investigar as influências de contexto, no nível estadual, na auto-avaliação de saúde de mulheres. Mulheres que viviam em estados situados no quintil inferior dos escores de índices femininos político e econômico (participação política, empregos e salários, autonomia econômica) referiram mais freqüentemente sua saúde como ruim $(\mathrm{OR}=1,14$; IC95\%: 1,01-1,28; OR = 1,29; IC95\%: 1,08-1,55; e OR = 1,30; IC95\%: 1,09-1,56, respectivamente), após o controle para características individuais. 
Síntese descritiva dos estudos multinível para efeitos de contexto na auto-avaliação de saúde, para país com amostra de pequenas áreas, 2005.

\begin{tabular}{|c|c|c|c|c|c|c|c|}
\hline \multirow{5}{*}{$\begin{array}{l}\text { Desfecho } \\
\text { auto-avaliação } \\
\text { de saúde/ } \\
\text { Prevalência de } \\
\text { saúde ruim }\end{array}$} & \multirow{5}{*}{$\begin{array}{c}\text { Escala geográfica } \\
\text { de abrangência/ } \\
\text { Características } \\
\text { da amostra/ } \\
\text { Aferição e \% } \\
\text { de resposta }\end{array}$} & \multirow{5}{*}{$\begin{array}{c}\text { Unidade espacial } \\
\text { de análise }\end{array}$} & \multirow{5}{*}{$\begin{array}{c}\text { Características } \\
\text { individuais }\end{array}$} & \multirow[t]{5}{*}{ Características contextuais } & \multicolumn{3}{|c|}{ Resultados para contexto } \\
\hline & & & & & \multirow[t]{4}{*}{$\begin{array}{c}\text { Significância } \\
\text { estatística }\end{array}$} & \multirow{4}{*}{\multicolumn{2}{|c|}{$\begin{array}{l}\text { Coeficientes de } \\
\text { regressão (DP) } \\
\text { ou odds ratio (IC) }\end{array}$}} \\
\hline & & & & & & & \\
\hline & & & & & & & \\
\hline & & & & & & & \\
\hline Dicotômico & País - Suécia & 837 SAMS & Idade/sexo & Care Need Index & $\mathrm{S}$ & $1,84(1,52$ & $2,22) *$ \\
\hline \multirow[t]{5}{*}{$24 \%$} & 9.240 residentes & (pequenas & Escolaridade & Towsend Score & $\mathrm{S}$ & $1,56(1,32$ & $1,85)$ * \\
\hline & 25 a 74 anos & áreas de & Índice de massa & & & & \\
\hline & Entrevista & mercado) & corporal & & & & \\
\hline & Resposta $80 \%$ & & Hábito de fumar & & & & \\
\hline & & & Inatividade física & & & & \\
\hline Dicotômico & 2 países - Reino & 238 vizinhanças & Idade & Coesão social (8 escalas) & & Mulheres & Homens \\
\hline $23 \%$ mulheres & Unido & 170 Inglaterra & Tipo de família & Relações familiares & $\mathrm{S} q$ & 0,107 & \\
\hline \multirow[t]{34}{*}{$24 \%$ homens } & 8.440 residentes & 68 Escócia & Classe social & & & $(0,038)$ & 0 \\
\hline & 16 anos ou mais & (setores postais) & Situação de & Relações de amizade & NS & & \\
\hline & Entrevista & & emprego & Participação & NS & & \\
\hline & Resposta 69\% a & & & Integração na sociedade & $\mathrm{S}$ 保 & 0,098 & 0,005 \\
\hline & $81 \%$ & & & & & $(0,036)$ & $(0,033)$ \\
\hline & Correio & & & Confiança & $\mathrm{S} q$ & 0,087 & 0,007 \\
\hline & & & & & & $(0,035)$ & $(0,034)$ \\
\hline & & & & Vínculo com a vizinhança & NS & & \\
\hline & & & & Tolerância & $\mathrm{S} q$ & 0,097 & 0 \\
\hline & & & & & & $(0,036)$ & \\
\hline & & & & Disposição para ajudar outras & NS & & \\
\hline & & & & pessoas & & & \\
\hline & & & & Infra-estrutura local (11 escalas) & & & \\
\hline & & & & Engajamento político (baixo) & $\mathrm{S} q$ & 0,111 & 0,007 \\
\hline & & & & & & $(0,038)$ & $(0,034)$ \\
\hline & & & & Representação política com & $\mathrm{S}$ q & 0,105 & 0,006 \\
\hline & & & & afiliação esquerda & & $(0,037)$ & $(0,034)$ \\
\hline & & & & Crime & $\mathrm{S}$ q & 0,116 & 0,008 \\
\hline & & & & & & $(0,039)$ & $(0,034)$ \\
\hline & & & & Acesso a cooperativas de & $\mathrm{S}$ q & 0,099 & 0 \\
\hline & & & & alimentos & & $(0,041)$ & \\
\hline & & & & Acesso a bancos e escritórios & $\mathrm{S} q$ & 0,093 & 0 \\
\hline & & & & & & $(0,038)$ & \\
\hline & & & & Serviços de saúde & $\mathrm{S} q$ & 0,101 & 0 \\
\hline & & & & & & $(0,044)$ & \\
\hline & & & & Recreação pública & NS & & \\
\hline & & & & Qualidade física do ambiente & $\mathrm{S}$ ㅇ & 0,091 & 0 \\
\hline & & & & (baixa) & & $(0,040)$ & \\
\hline & & & & Presença de automóveis de valor & $\mathrm{S}$ ㅇ & 0,114 & 0,002 \\
\hline & & & & (baixo) & & $(0,038)$ & $(0,033)$ \\
\hline & & & & Acesso a transporte privado & $\mathrm{S}$ ㅇ & 0,107 & 0,005 \\
\hline & & & & (baixo) & & $(0,038)$ & $(0,033)$ \\
\hline & & & & Desemprego (alto) & $\mathrm{S}$ ㅇ & 0,087 & 0,006 \\
\hline & & & & & & $(0,035)$ & $(0,034)$ \\
\hline
\end{tabular}

(continua) 


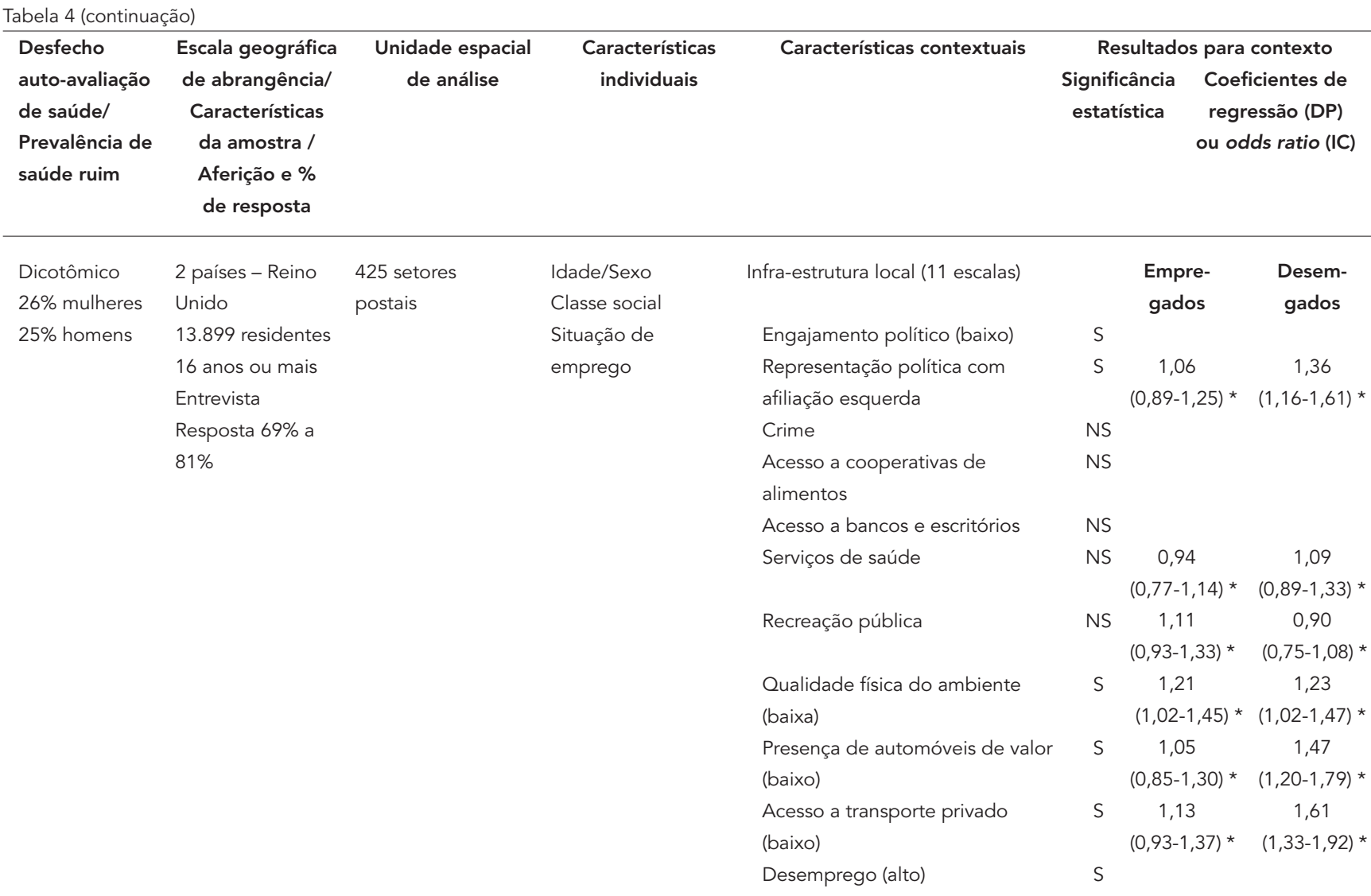

\footnotetext{
S: significativo; So : significativo somente para as mulheres; NS: Não significativo; SAMS: pequenas áreas de mercado.
}

* Valores referentes ao odds ratio (IC).

Dois estudos investigaram comunidades norte-americanas valendo-se das mesmas fontes de dados. O primeiro objetivou abordar os efeitos da confiança social individual e contextual sobre a saúde 43 . De acordo com seus resultados, controladas as variáveis demográficas e sócio-econômicas individuais, altos níveis de confiança social no nível da comunidade estão associados à baixa probabilidade de referir saúde ruim. Entretanto, controlando-se para a percepção de confiança individual, o efeito da confiança no nível comunitário deixou de ser significativo. Os autores observaram que ocorreram interações complexas entre os diferentes níveis de confiança (individual e de comunidade), sugerindo que as pesquisas sobre saúde da população e capital social devem considerar a natureza dos efeitos cruzados de comunidade ou vizinhança. O segundo estudo 44 investigou determinantes individuais da autoavaliação de saúde e de felicidade, assim como a variação dos desfechos no nível de comunidade. A participação do nível de comunidade na variação da auto-avaliação de saúde individual, isoladamente, não foi significativa.
Dois estudos investigaram a desigualdade de renda em comunidades chilenas e sua influência na auto-avaliação de saúde. No primeiro 45 , foram consideradas 285 comunidades e foi examinada a variabilidade para 13 regiões, nas quais as comunidades são aninhadas. A escala de região não foi significativa para a variação da auto-avaliação de saúde. Os autores relataram que, controlando para o conjunto de variáveis individuais, houve um efeito significativo, não linear, da desigualdade de renda de comunidade na auto-avaliação de saúde. Indivíduos que vivem em comunidades mais desiguais apresentaram aproximadamente $5 \%$ mais chance de referir saúde ruim do que aqueles que vivem em comunidades mais igualitárias. No segundo estudo 46 , foram consideradas 285 comunidades e o nível de família, além do individual. Os principais resultados foram o efeito significativo da desigualdade de renda no nível de comunidade na chance de auto-avaliação de saúde ruim (OR = 1,22; IC95\%: 1,04-1,43), após terem sido controlados os fatores individuais e os efeitos de renda da família e da comunidade. 
Síntese descritiva dos estudos multinível para efeitos de contexto na auto-avaliação de saúde, para país com amostra de grandes áreas, 2005.

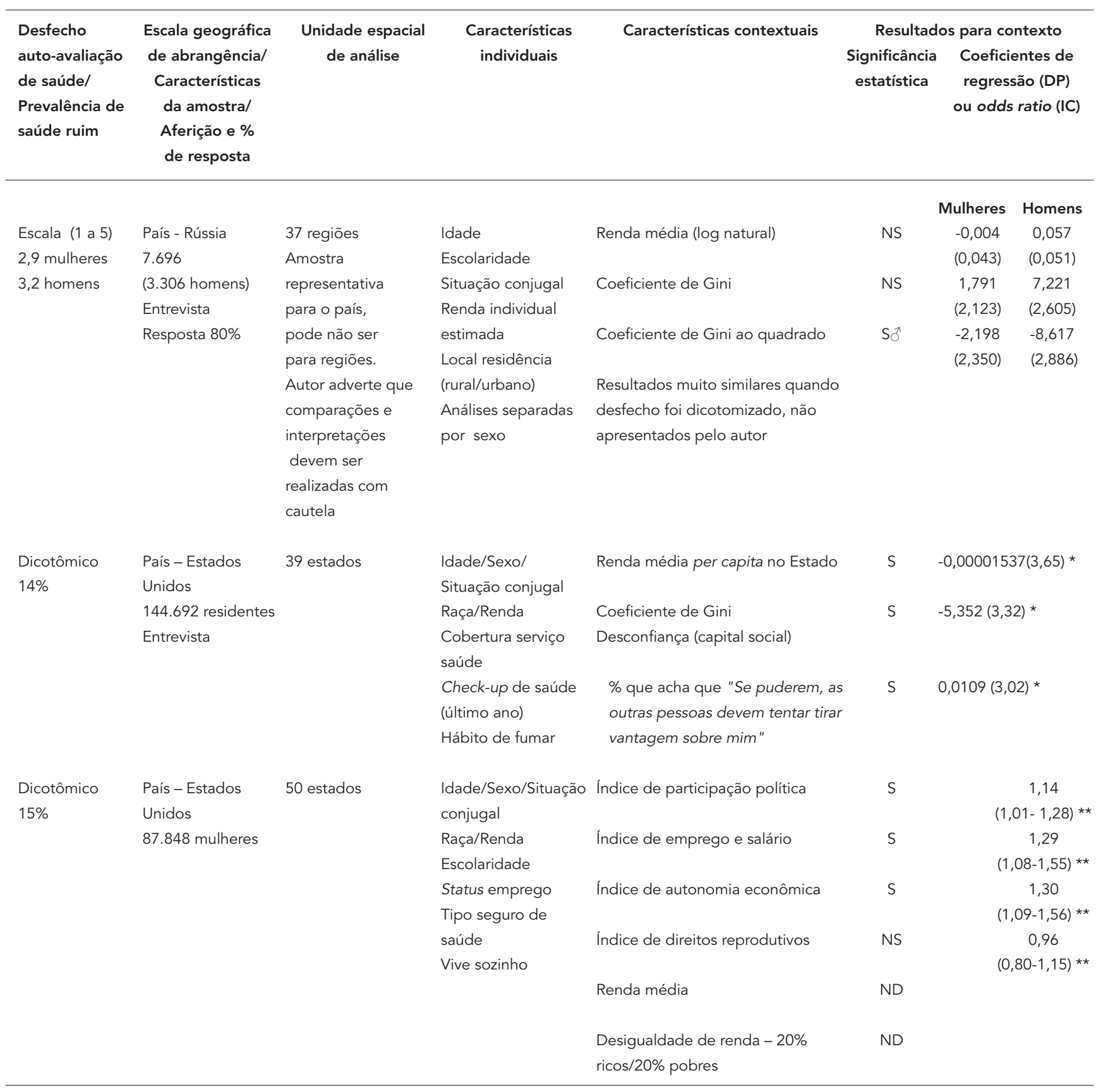

(continua) 
Tabela 5 (continuação)

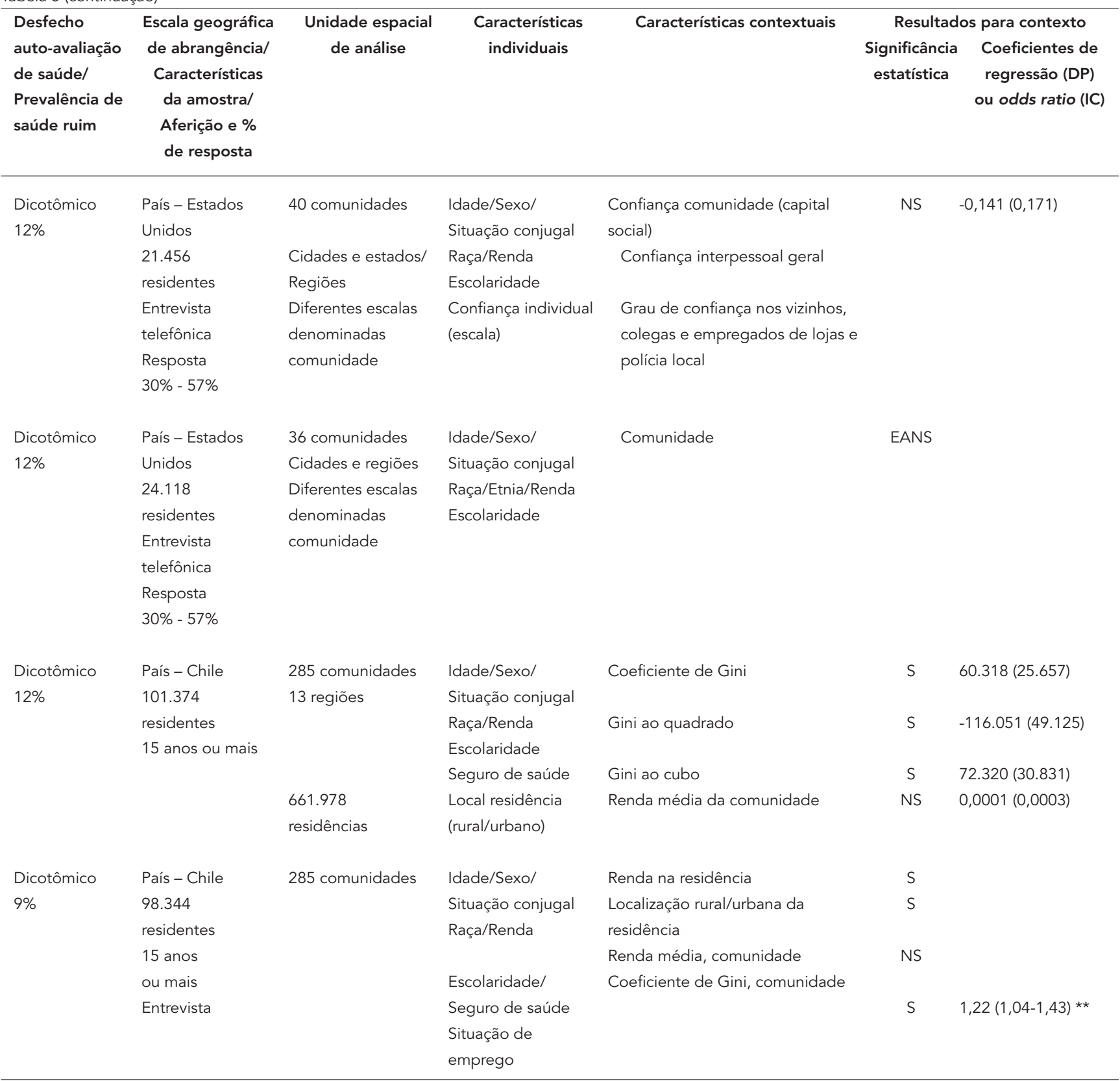

S: significativo; Ş̊: significativo somente para os homens; NS: não significativo; ND: não descrito; EANS: efeito aleatório do nível de contexto não significativo.

* Entre parênteses coeficiente dividido pelo desvio padrão;

** Valores referentes ao odds ratio (IC). 
Características de contexto sócioeconômicas, físicas e psicossociais estudadas

Dentre os 18 artigos identificados, indicadores sócio-econômicos foram estudados em 14 . Dentre esses, em 10 foram estudados isoladamente, em três, também foram estudados indicadores psicossociais $35,37,41$, e em apenas um as três dimensões de contexto foram investigadas: sócio-econômica; psicossocial; e do ambiente físico 12 . Variáveis do ambiente físico em conjunto com psicossociais foram estudadas em um artigo 38. Um, utilizou apenas variáveis psicossociais 43 e um utilizou somente variáveis do ambiente físico 39 .

A área geográfica foi estudada apenas nominalmente (como localização, sem indicadores de características próprias), em apenas um artigo 44 . Este achado reflete maior preocupação com o estudo de fatores sócio-econômicos de contexto e a busca recente da identificação de características físicas e psicossociais envolvidas nos processos que atuam no contexto de moradia que podem influenciar na saúde.

Os indicadores de contexto estudados, conforme a dimensão das características de contexto, tanto como os individuais, estão representados na Figura 2.

Existiu grande diversidade de indicadores sócio-econômicos. O indicador mais utilizado foi o de renda média seguido pelo coeficiente de Gini, heterogeneidade étnica e migração, escolaridade e riqueza. A maioria dos estudos optou por indicadores simples que não resultaram de combinação entre variáveis de fatores ou escalas. Somente em seis artigos os índices compostos estiveram presentes.

Os indicadores de ambiente psicossocial foram investigados em seis artigos, por intermédio de medidas distintas de capital social 37,41,43, de eficácia coletiva 12,35 , ou de coesão social 38 . A diversidade de indicadores dificultou a comparação entre os estudos. O capital social medido como desconfiança mediante apenas uma pergunta 41 foi significativo, em conjunto com indicadores sócio-econômicos de contexto. Quando medido em escalas, não o foi 37,43. A eficácia coletiva foi medida da mesma forma em dois estudos. Apresentou efeito significativo em população de maiores de 18 anos, na cidade de Chicago 12 , mas não para a subpopulação maior de 55 anos de idade, em que os fatores sócio-econômicos de contexto como riqueza e estabilidade residencial tiveram efeitos mais importantes sobre a autoavaliação de saúde 35 . A coesão social, medida por oito escalas, na Inglaterra e Escócia 38, não foi significativa para homens. Para as mulheres, aspectos da família, integração na sociedade, confiança e tolerância apresentaram efeitos contextuais importantes associados com melhor auto-avaliação de saúde.

As características do ambiente físico e infraestrutura foram medidas em somente três artigos, e dois utilizaram as mesmas escalas 38,39 . Na população da Inglaterra e Escócia, em análise conjunta para homens e mulheres, o desemprego alto, o baixo acesso a transporte privado, a baixa qualidade física do ambiente e o baixo engajamento político apresentaram associação com pior auto-avaliação de saúde ${ }^{38}$. Quando as mesmas características foram analisadas de modo separado para cada sexo, em conjunto com escalas de coesão social, elas não apresentaram associação significativa com a auto-avaliação de saúde dos homens, em nenhuma das suas escalas de infra-estrutura local do ambiente físico. Para as mulheres, somente a escala de recreação pública não foi significativa ${ }^{39}$. No artigo que mediu escalas de desordem física e adequação dos serviços de saúde locais, em Chicago ${ }^{12}$, somente a primeira apresentou efeito significativo. Naquele estudo, um nível maior de desordem física do ambiente esteve relacionado com pior autoavaliação de saúde, em conjunto com fatores sócio-econômicos e eficácia coletiva.

\section{Discussão}

No período analisado, houve um crescimento importante de estudos multinível de fatores envolvidos na determinação da auto-avaliação de saúde, acompanhado da ampliação das dimensões de indicadores de contexto investigados e do aprofundamento da complexidade dos modelos teóricos.

Os estudos do final da década de 1990 até 2002 concentraram-se na investigação de indicadores sócio-econômicos como determinantes contextuais da auto-avaliação de saúde. A partir de 2003, verifica-se que as dimensões psicossociais e físicas do ambiente começaram a ser incorporadas aos modelos de investigação. Além disso, a participação da dimensão sócio-econômica passou a ser estudada de forma mais detalhada. Várias medidas de desigualdade de renda foram testadas 11, e surgiu a discussão do poder de determinação de indicadores de pobreza em comparação aos de riqueza em relação à autoavaliação de saúde 7,8 .

De acordo com os resultados de 15 dentre os 18 estudos revisados, houve associação significativa entre, pelo menos, uma medida de características de vizinhança e auto-avaliação de saúde. Apesar disso, a literatura ainda é reduzida para a validação externa das associações obser- 


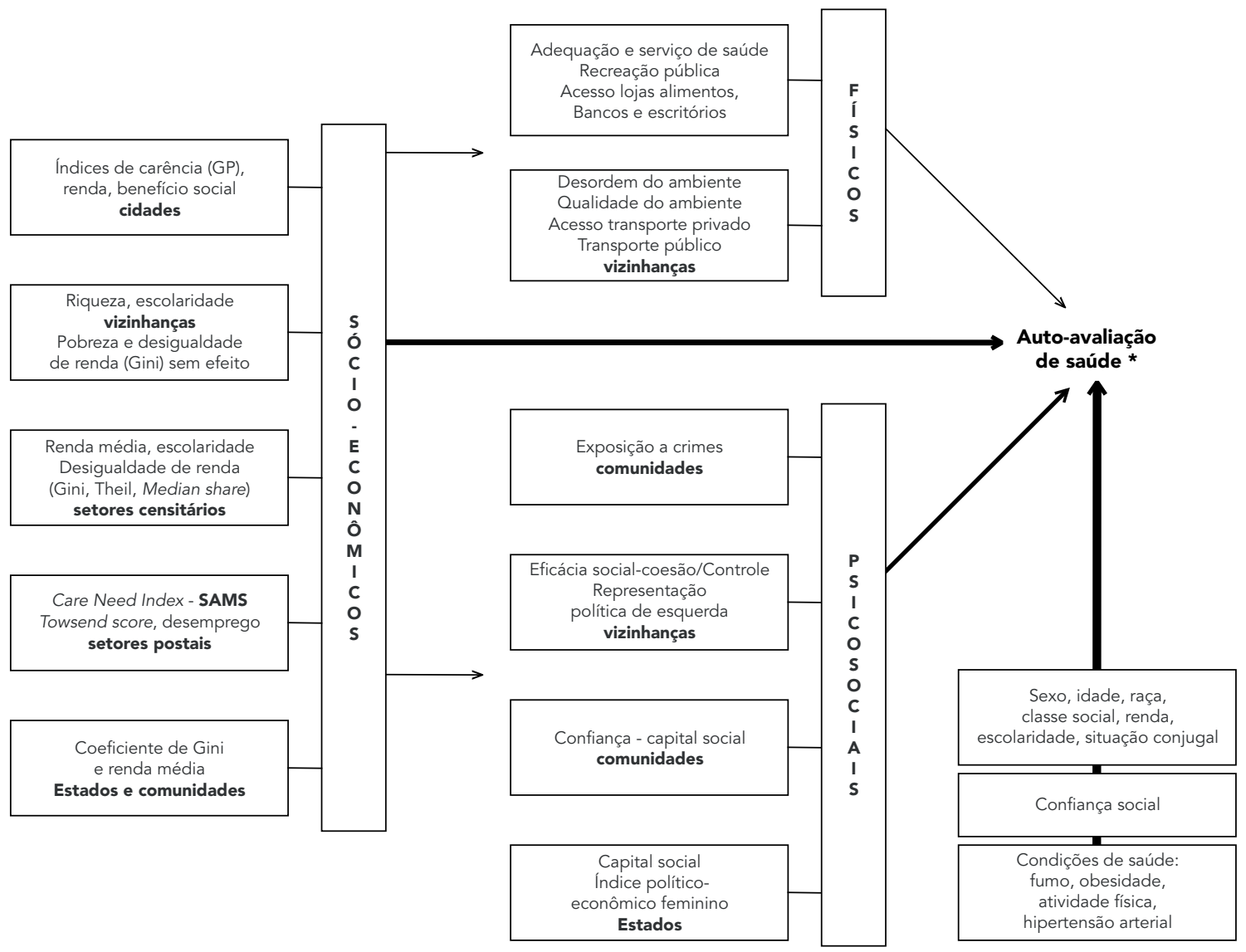

SAMS: pequenas áreas de mercado.

* A espessura das setas é correspondente à força de associação evidenciada.

vadas, uma vez que não há estudos replicados que utilizem as mesmas co-variáveis e mesmas categorias de medidas de exposição de contexto, para unidades de análise geográficas semelhantes. Por conseguinte, os resultados apresentados permitem a composição de um panorama preliminar da magnitude dos efeitos de vizinhança na auto-avaliação de saúde, para além dos efeitos das características individuais (Figura 2).

Nos estudos revisados, as associações encontradas entre as características de contexto e a auto-avaliação de saúde corroboram a hipótese de que o contexto de moradia influencia a saúde individual. Piores condições sócio-econômicas do ambiente afetam negativamente a saúde, aumentando a chance de auto-avaliação de saúde ruim. Todos os estudos, embora tenham utilizado diferentes indicadores, apresentaram resultados que mostram associação neste mesmo sentido. Áreas mais carentes (medida pelos índices GP, CNI, Towsend), com menos riqueza, com maior desigualdade de renda, contribuem para uma pior auto-avaliação de saúde.

Além dos níveis de renda da vizinhança, a desigualdade sócio-econômica também exerce impacto importante na auto-avaliação de saúde. Os resultados sugerem que indicadores de desigualdade refletem aspectos sócio-econômicos distintos daqueles expressados pela renda absoluta 11 . Outra questão importante é o fato de que em países onde a pobreza absoluta é relativamente rara, a carência relativa torna-se mais importante para analisar os impactos de fatores sócio-econômicos na saúde (Wilkinson, 1996, apud Malmström 
et al. 17). Por outro lado, no Brasil e países em desenvolvimento, variáveis de carência absoluta ainda são importantes marcadores contextuais da saúde individual.

As características sócio-econômicas do nível de vizinhança são muito mais colineares do que os fatores sócio-econômicos individuais, por isso é importante especificar o nível de efeito de contexto. Para entender o conjunto do ambiente social em relação à saúde, a interação entre fatores sócio-econômicos da vizinhança e o nível sócio-econômico individual deve de ser considerado. Caso eles sejam omitidos, os modelos ficam incompletos e os resultados potencialmente distorcidos. Sem o nível individual de informação, as variáveis de nível de contexto podem funcionar parcial ou completamente como marcadores dos atributos individuais, cujo impacto no desfecho de saúde permanece desconhecido. Por outro lado, se não dispor de medida no nível de contexto, o impacto das características individuais pode ficar obscurecido.

A incorporação da dimensão das características físicas e de infra-estrutura do ambiente e da dimensão psicossocial dos processos sociais coletivos é recente. Os resultados desses estudos mostraram que, apesar de que em menor intensidade do que o impacto dos indicadores sócioeconômicos, as características físicas (como desordem física da vizinhança) e as características psicossociais são fatores contextuais importantes na determinação da auto-avaliação de saúde. Os aspectos físicos e sócio-políticos do ambiente afetam de forma diferenciada a auto-avaliação de saúde de homens e mulheres 38,39. Para as mulheres, o impacto das características físicas e psicossociais da vizinhança na auto-avaliação de saúde é maior. Algumas, mas nem todas as características físicas estudadas do contexto de vizinhança, estiveram associadas à auto-avaliação de saúde e podem ser indicadores importantes que devem servir de foco para o planejamento de ações e intervenções de saúde pública.

Em relação às fontes de informação para medida de características de contexto, observa-se que a maior parte dessas características foi mensurada mediante agregação de respostas individuais. Ainda que esta seja uma forma fácil de obtenção de medidas, é importante que haja um aprofundamento da investigação das propriedades intrínsecas ao nível ecológico (coletivo). As características de contexto envolvidas nos processos coletivos são propriedades distintas da soma de medidas individuais. Muitos estudos de efeitos de contexto na saúde tendem a ser direcionados pela disponibilidade de dados, permanecendo no estudo de medidas globais de circunstâncias materiais derivadas de censos ou outras pesquisas populacionais. Maior atenção à conceituação, à operacionalização e à mensuração direta de características específicas do ambiente social e material que afetam a saúde deve ser desenvolvida visando aprofundar os estudos de efeitos de contexto.

Alguns estudos investigaram características de contexto por meio de escalas compostas por diversos fatores. Medidas de características de contexto que se valham de índices compostos por um grande número de variáveis podem ser uma solução para enfrentar o problema da grande colinearidade entre essas variáveis; todavia, por outro lado, podem levar a que os efeitos independentes e interativos de cada variável componente sejam obscurecidos no valor medido final. Os índices podem mascarar a variação entre áreas, ou seja, duas áreas com o mesmo escore final podem diferir nos valores de variáveis que contribuem para aquele escore 47 .

Os recortes territoriais para delimitação de unidades geográficas de análise foram muito diversos, dificultando a comparação dos resultados apresentados. Em parte, a diferença entre a magnitude das associações encontradas deve-se ao fato do uso de diferentes unidades espaciais de análise de características de contexto (setores censitários, vizinhanças, estados) e de diferentes escalas de representação (país, estados ou cidades).

É importante considerar-se que um dos passos essenciais para a construção de indicadores de contexto de moradia éa referência de informações a unidades espaciais discretas. Dado que muitos indicadores de saúde e qualidade de vida se referem a unidades espaciais, o geoprocessamento se apresenta como ferramenta de escolha para a organização e análise de dados, por meio de SIG 48 . O georreferenciamento de dados de saúde, população e ambiente pressupõe a escolha de unidades mínimas de agregação de dados, coerentes com o fenômeno a ser analisado. A opção impõe uma escala de análise que condiciona os resultados visuais e estatísticos obtidos 49 .

Uma questão central para pesquisadores e formuladores de políticas públicas, dado o espectro de possibilidades de definição de vizinhança, é identificar qual a melhor maneira de definir as unidades de vizinhança para embasar estudos, programas e intervenções. Claramente, não há uma maneira universal de delinear a vizinhança como uma unidade. Entretanto, vizinhanças devem ser identificadas e definidas mediante um processo guiado por objetivos específicos, pelo entendimento teórico da importância da vizinhança num contexto particular. Tal abordagem deve considerar a escala e o impacto desejado, com a identificação de quais elementos são os mais importantes para sustentar estratégias e 
ações de saúde dirigidas, e pelo conhecimento das dinâmicas política, social e econômica onde se dá a vida local 26 .

\section{Considerações finais}

$\mathrm{O}$ ambiente social inclui a vizinhança onde se vive e as regras (procedimentos, políticas) que criamos para organizar nossas vidas. Estudos que objetivem abordar as relações entre ambiente social e saúde devem ser baseados nessas observações fundamentais 50 . Destacam-se como pontos importantes para o delineamento de estudos multinível: a definição de quais variáveis contextuais são relevantes para eventos (desfechos de saúde) específicos; e a seleção da unidade espacial apropriada para análise, definindo-se claramente os limites de vizinhança 11 . Macintyre et al. 51 e Kaplan 52 chamam atenção para a necessidade de definir os limites de vizinhança e quais processos atuam nas diferentes escalas geográficas (bairros, estados, países), assim como a justificativa etiológica na definição de fatores a serem estudados (em cada escala) em relação ao desfecho. Espera-se que os resultados das pesquisas de efeitos de contexto na saúde, que levarem esses aspectos em consideração, permitam a configuração de um conjunto coerente e consistente de características de vizinhança que possam ser alvo de intervenções para minimização de riscos para diferentes agravos à saúde.

\section{Resumo}

A influência de características do local de moradia na auto-avaliação de saúde ainda é um tema pouco estudado, especialmente no Brasil. Neste trabalho realizou-se uma síntese das evidências disponíveis a respeito da associação entre fatores contextuais e auto-avaliação de saúde. Foi realizada uma revisão sistemática de artigos publicados entre janeiro de 1995 e agosto de 2005, nas bases ISI, PubMed e LILACS, utilizando-se os termos neighbourhood ou neighborhood, ecological, contextual, environment, community, em combinação com self-rated health, self-reported health, e também com multilevel ou hierarchical. Foram revisados 18 artigos, cuja maior parte analisou características sócio-econômicas; alguns investigaram variáveis psicossociais, poucos incluíram indicadores do ambiente físico. As unidades de referência espacial variaram desde setores censitários até estados. As diferenças entre as escalas de análise do nível contextual, o uso de diversos indicadores e suas diferentes categorizações dificultaram a comparação direta entre os resultados encontrados. As associações encontradas corroboram a hipótese de que o contexto de moradia influencia a auto-avaliação de saúde, para além do efeito dos fatores individuais. Piores condições sócio-econômicas do ambiente afetam negativamente a saúde, aumentando a chance de auto-avaliação de saúde ruim. Áreas mais carentes, com mais pobreza ou menos riqueza, com maior desigualdade de renda, aumentaram a prevalência de auto-avaliação de saúde pior. As características físicas e psicossociais da vizinhança também são fatores importantes na determinação da auto-avaliação de saúde.

Nível de Saúde; Fatores Socioeconômicos; Literatura de Revisão 


\section{Colaboradores}

S. M. Santos participou da concepção do artigo, realizou a estruturação do protocolo e a revisão bibliográfica, a análise e interpretação dos dados compilados e escreveu o artigo. D. Chor e G. L. Werneck participaram da concepção do artigo, contribuíram com a análise e interpretação dos resultados e escreveram o artigo. E. S. F. Coutinho contribuiu com a concepção do protocolo de revisão bibliográfica e na revisão do artigo.

\section{Agradecimentos}

Os autores agradecem ao pesquisador Christovam Barcellos (Instituto de Comunicação e Informação Científica e Tecnológica em Saúde, Fundação Oswaldo Cruz) por suas atenciosas críticas e sugestões. Este estudo faz parte do projeto A Importância da Vizinhança nos Niveis de Saúde Individual: Determinação Ecológica e Individual, e Auto-avaliação de Saúde que conta com fomento da Coordenação de Aperfeiçoamento de Pessoal de Nível Superior (CAPES), pela concessão de bolsa de doutorado. Este trabalho também foi parcialmente financiado com recursos do Conselho Nacional de Desenvolvimento Científico e Tecnológico (CNPq) - processo 308133/2004-8 (G. L. W.) - e do projeto 400090/2006-6 (PAPES) - CNPq/FIOCRUZ.

\section{Referências}

1. Idler EL, Benyamini Y. Self-rated health and mortality: a review of twenty-seven community studies. J Health Soc Behav 1997; 38:21-37.

2. Jylhä M, Gurainik JM, Ferrucci L, Jokela J, Heikkinen E. Is self-rated health comparable across cultures and genders? J Gerontol B Psychol Sci Soc Sci 1998; 53:S144-52.

3. Berkman LF, Kawachi I. Social epidemiology. New York: Oxford University Press; 2000.

4. Dachs JNW. Determinantes das desigualdades na auto-avaliação do estado de saúde no Brasil: análise dos dados da PNAD/1998. Ciênc Saúde Coletiva 2002; 7:641-57.

5. Lima-Costa MF, Firmo JOAF, Uchôa E. Differences in self-rated health among older adults according to socioeconomic circumstances: the Bambuí Health and Aging Study. Cad Saúde Pública 2005; 21:830-9.

6. Szwarcwald CL, Souza-Júnior PRB, Esteves MAP, Damascena GN, Viacava F. Determinantes sóciodemográficos da auto-avaliação da saúde no Brasil. Cad Saúde Pública 2005; 21 Suppl:S54-64.

7. Kennedy BP, Kawachi I, Glass R, Prothrow-Stigh D. Income distribution, socioeconomic status, and self-rated health in the United States: multilevel analysis. BMJ 1998; 317:917-21.

8. Bobak M, Pikhart H, Rose K, Hertzman C, Marmot M. Socioeconomic factors, material inequalities, and perceived control in self-rated health: crosssectional data from seven pot-communist countries. Soc Sci Med 2000; 51:1343-50.

9. Lindström M, Sundquist J, Östergren P-O. Ethnic differences in self reported health in Malmö in southern Sweden. J Epidemiol Community Health 2001; 55:97-103.
10. Aberg-Ynwe M, Diderichsen F, Whitehead M, Holland P, Burstrom B. The role of income differences in explaining social inequalities in self-rated health in Sweden and Britain. J Epidemiol Community Health 2001; 55:556-61.

11. Diez-Roux AV. Multilevel analysis in public health research. Annu Rev Public Health 2000; 21:171-92.

12. Wen M, Browning CR, Cagney KA. Poverty, affluence, and income inequality: neighborhood economic structure and its implications for health. Soc Sci Med 2003; 57:843-60.

13. Ross CE. Walking, exercising, and smoking: does neighborhood matter? Soc Sci Med 200; 51:265-74.

14. Caughy MO, O'Campo PJ, Mutaner C. When being alone might be better: neighborhood poverty, social capital, and child mental health. Soc Sci Med 2003; 57:227-37.

15. Macintyre S, Maciver S, Sooman A. Area, class and health: should we be focusing on places or people? J Soc Policy 1993; 22:213-34.

16. Lynch J, Kaplan G. Socioeconomic position. In: Berkman L, Kawachi I, editors. Social epidemiology. New York: Oxford University Press; 2000. p. 13-35.

17. Malmtröm M, Sundquist J, Johanson S-E. Neighborhood environment and self-reported health status: a multilevel analysis. Am J Public Health 1999; 89:1181-6.

18. Subramanian SV, Kawachi I. Whose health is affected by income inequality? A multilevel interaction analysis of contemporaneous and lagged effects of state income inequality on individual self-rated health in the United States. Health Place 2006; 12:141-56. 
19. Sampson RJ, Raudenbush SW. Systematic social observation of public spaces: a new look at disorder in urban neighborhoods. AJS 1999; 105:603-51.

20. Cohen DA, Mason K, Bedimo A, Scribner R, Basolo V, Farley TA. Neighborhood physical conditions and health. Am J Public Health 2003; 93:467-71.

21. Bobak M, Pikhart H, Rose K, Hertzman C, Marmot M. Socioeconomic factors, material inequalities, and perceived control in self-rated health: crosssectional data from seven pot-communist countries. Soc Sci Med 2000; 51:1343-50.

22. Kawachi I, Berkman LF. Neighborhoods and health. New York: Oxford University Press; 2003.

23. Kawachi I, Kennedy BP, Glass R. Social capital and self-rated health: A contextual analysis (comment). Am J Public Health 1999; 89:1187-93.

24. Lochner KA, Kawachi I, Brennam RT, Buka SL. Social capital and neighborhood mortality rates in Chicago. Soc Sci Med 2003; 56:1797-805.

25. Sampson RJ, Morenoff JD, Earls F. Beyond social capital: spatial dynamics of colletive efficacy for children. Am Sociol Rev 1999; 64:633-60.

26. Chaskin RJ. Perspectives on neighborhood and community: a review of the literature. Soc Serv Rev 1997; 71:521-7.

27. Buka SL, Brennan RT, Rich-Edwards JW, Raudenbush SW, Earls F. Neighborhood support and the birth weight of urban infants. Am J Epidemiol 2003; 157:1-8.

28. Lindström M, Merlo J, Östergren P. Social capital and sense of insecurity in the neighbourhood: a population-based multilevel analysis in Malmö, Sweden. Soc Sci Med 2003; 56:1111-20.

29. Sampson RJ. The neighborhood context of wellbeing. Perspect Biol Med 2003; 46(3 Suppl):S53-64.

30. Patel KV, Eschbach K, Rudkin LL, Peek MK, Markides KS. Neighborhood context and self-rated health in older Mexican Americans. Ann Epidemiol 2003; 13:620-8

31. Morenoff JD, Sampson RJ, Raudenbush SW. Neighborhood structure, social processes, and the spatial dynamics of urban violence. Criminology 2001; 39:517-60.

32. Reijneveld SA. The impact of individual and area characteristics on urban socioeconomic differences in health and smoking. Int J Epidemiol 1998; 27:33-40.

33. Reijneveld SA. Neighborhood socioeconomic context and self reported health and smoking: a secondary analysis of data on seven cities. J Epidemiol Community Health 2002; 56:935-42.

34. Browning CR, Cagney KA, Wen M. Explaining variation in health status across space and time: implications for racial and ethnic disparities in selfrated health. Soc Sci Med 2003; 57:1221-35.

35. Cagney KA, Browning CR, Wen M. Racial disparities in self-rated health at older ages: what differences does the neighborhood make? J Gerontol B Psychol Sci Soc Sci 2005; 60:S181-90.

36. Hou F, Myles J. Neighborhood inequality, neighborhood affluence and population health. Soc Sci Med 2005; 60:1557-69.

37. Veenstra G. Location, location, location: contextual and compositional health effects of social capital in British Columbia, Canada. Soc Sci Med 2005; 60:2059-71.
38. Stafford M, Cummins S, Macintyre S. Gender differences in the associations between health and neighborhood environment. Soc Sci Med 2005; 60:1681-92.

39. Cummins S, Stafford M, Macintyre S, Marmot M, Ellaway A. Neighborhood environment and its associations with self rated health: evidence from Scotland and England. J Epidemiol Community Health 2005; 59:207-13.

40. Carlson P. Relatively poor, absolutely ill? A study of regional income inequality in Russian and its possible health consequences. J Epidemiol Community Health 2005; 59:389-94.

41. Subramanian SV, Kawachi I, Kennedy BP. Does the state you live in make a difference? Multilevel analysis of self-rated health in the US. Soc Sci Med 2001; 53:9-19.

42. Jun HI, Subramanian SV, Gortmaker S, Kawachi I. A multilevel analysis of women's status and selfrated health in the United States. J Am Med Womens Assoc 2004; 59:172-80.

43. Subramanian SV, Kim OJ, Kawachi I. Social trust and self-rated health in US communities: a multilevel analysis. J Urban Health 2002; 79(4 Suppl 1): S21-34.

44. Subramanian SV, Kim OJ, Kawachi I. Covariation in the socioeconomic determinants of self rated health and happiness: a multivariate multilevel analysis of individuals and communities in the USA. J Epidemiol Community Health 2005; 59: 664-9.

45. Subramanian SV, Delgado IB, Jandue LH, Kawachi I, Vega JM. Inequidad de ingreso y autopercepción de salud: un análisis desde la perspectiva contextual en las comunas chilenas. Rev Med Chil 2003; 131:321-30.

46. Subramanian SV, Delgado IB, Vega J, Kawachi I. Income inequality and health: multilevel analysis of Chilean communities. J Epidemiol Community Health 2003; 57:844-8.

47. Picket KE, Pearl M. Multilevel analyses of neighbourhood socioeconomic context and health outcomes: a critical review. J Epidemiol Community Health 2001; 55:111-22.

48. Briggs DJ, Elliot P. The use of geographical information system on environment and health. World Health Stat Q 1995; 48:85-94.

49. Barcellos C, Santos SM. Colocando dados no mapa: a escolha da unidade de agregação e integração de bases de dados em saúde e ambiente através do geoprocessamento. Inf Epidemiol SUS 1997; 6: 21-9.

50. Yen IH, Syme SL. The social environment and health: a discussion of the epidemiologic literature. Annu Rev Public Health 1999; 20:287-308.

51. Macintyre S, Ellaway A, Cummins S. Place effects on health: how can we conceptualize, operationalise and measure them? Soc Sci Med 2002; 55: 125-39.

52. Kaplan GA. What's wrong with social epidemiology, and how we can make better? Epidemiol Rev 2004; 26:124-35.

Recebido em 28/Set/2006

Versão final reapresentada em 13/Abr/2007 Aprovado em 20/Abr/2007 